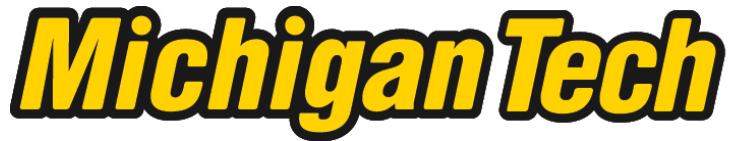 \\ Michigan Technological University Create the Future Digital Commons @ Michigan Tech
}

\section{Geotechnical Data and Numerical Analysis of Edifice Collapse and Related Hazards at Pacaya Volcano, Guatemala}

Lauren N. Schaefer

Michigan Technological University

Follow this and additional works at: https://digitalcommons.mtu.edu/etds

Part of the Geology Commons

Copyright 2012 Lauren N. Schaefer

\section{Recommended Citation}

Schaefer, Lauren N., "Geotechnical Data and Numerical Analysis of Edifice Collapse and Related Hazards at Pacaya Volcano, Guatemala", Master's Thesis, Michigan Technological University, 2012.

https://doi.org/10.37099/mtu.dc.etds/470

Follow this and additional works at: https://digitalcommons.mtu.edu/etds

Cart of the Geology Commons 


\title{
GEOTECHNICAL DATA AND NUMERICAL ANALYSIS OF EDIFICE COLLAPSE AND RELATED HAZARDS AT PACAYA VOLCANO, GUATEMALA
}

\author{
By \\ Lauren N. Schaefer

\begin{abstract}
A THESIS
Submitted in partial fulfillment of the requirements for the degree of MASTER OF SCIENCE In Geology
\end{abstract}

\section{MICHIGAN TECHNOLOGICAL UNIVERSITY 2012}

(C) 2012 Lauren N. Schaefer 
This thesis has been approved in partial fulfillment of the requirements for the Degree of MASTER OF SCIENCE in Geology.

Department of Geological and Mining Engineering and Sciences

\author{
Thesis Advisor: Dr. Thomas Oommen
}

Committee Member: $\quad$ Dr. Alessandro Tibaldi

Committee Member: Dr. Claudia Corazzato

Department Chair: Dr. Wayne Pennington 


\section{TABLE OF CONTENTS}

PREFACE

ACKNOWLEDGEMENTS ..................................................................................

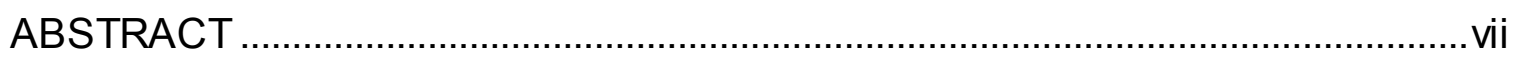

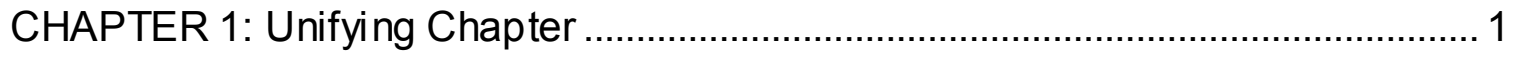

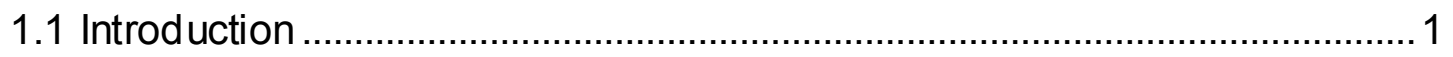

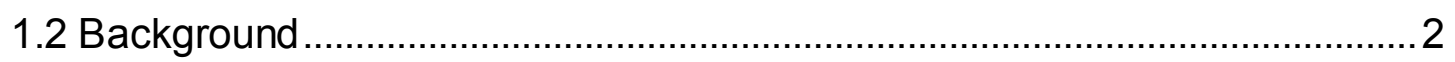

1.2.1 Volcanic Avalanches and their Hazards ...........................................

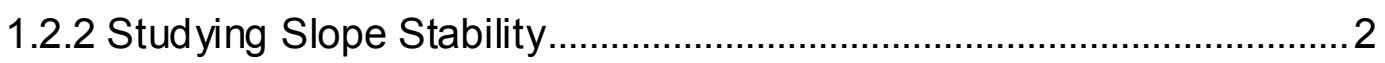

1.2.3 The Example of Pacaya Volcano ............................................................ 4

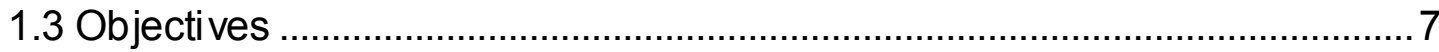

1.4 Major Findings of Technical Work ...........................................................

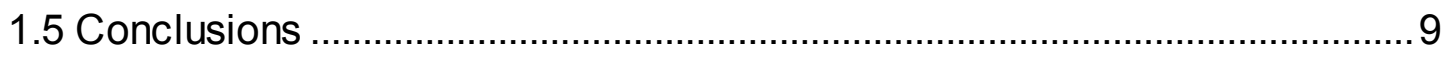

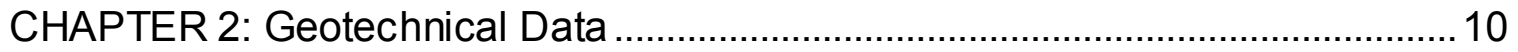

2.1 Rock mass strength and elastic properties .............................................10

2.2 Physical and mechanical properties of intact rock and discontinuities .....11

2.2.1 Physical properties ...........................................................................11

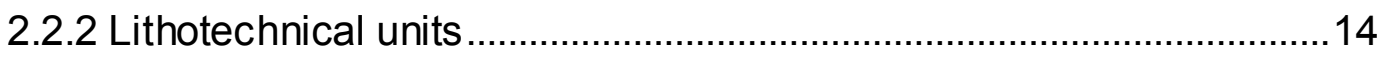

2.2.3 Quantitative description of rock masses and discontinuities.............16

2.2.4 Schmidt Hammer tests ................................................................... 18

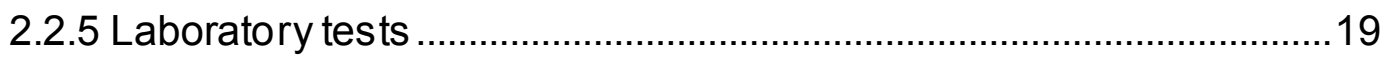

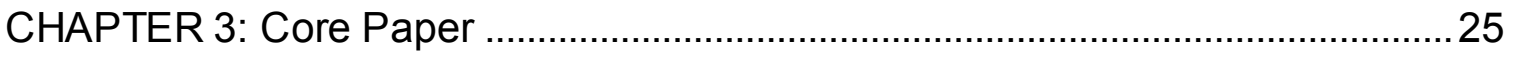

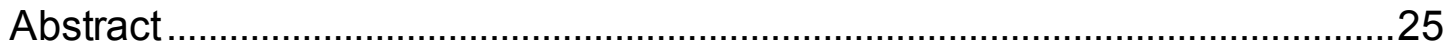

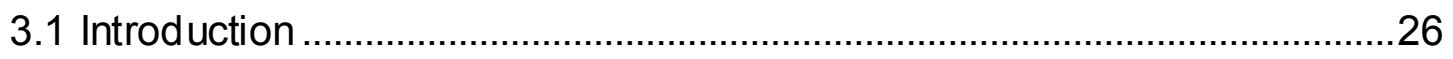

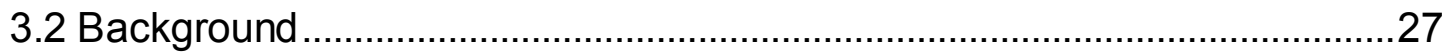

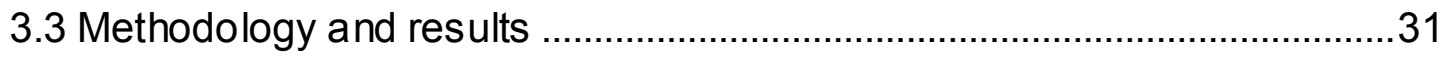

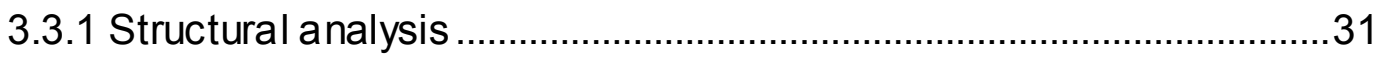


3.3.2 Rock mass properties .33

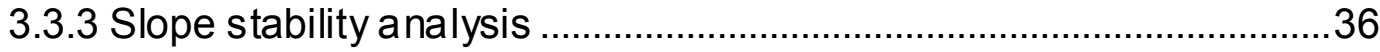

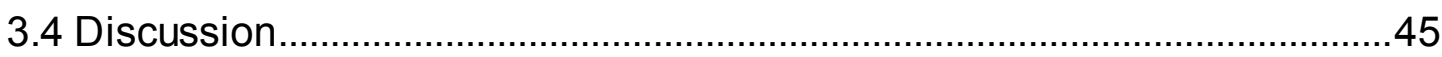

3.4.1 The lesson from the previous geological history ..............................45

3.4.2 Slope stability evaluation................................................................46

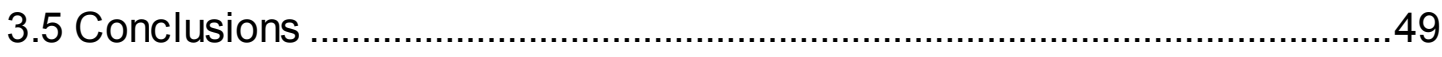

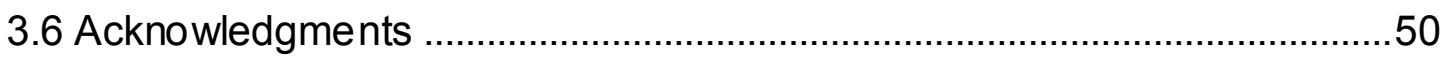

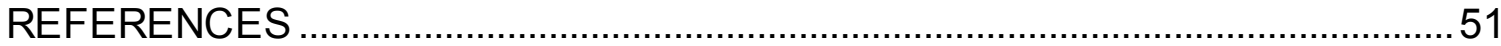

APPENDIX A: Rose diagrams (strike direction) of principal discontinuities at

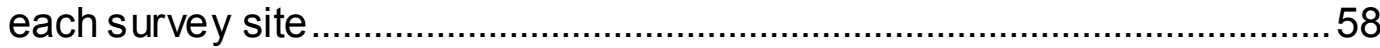

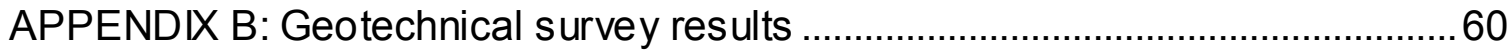




\section{PREFACE}

The core paper included in this thesis, "An integrated field-numerical approach to assess slope stability hazards at volcanoes: the example of Pacaya, Guatemala," includes several co-authors whose expertise and guidance has allowed the paper to be possible. It should be noted that the majority of paper was written by myself, and all of the tables and figures were made by myself. Additionally, the field work and computer modeling was analyzed and processed by myself. 


\section{ACKNOWLEDGEMENTS}

This research was performed in the framework of the USA-Italy-France Atlantis INVOGE (International Geologic Masters in Volcanology and Geotechniques) project, and under the umbrella of the International Lithosphere Program - Task Force II. Additionally, this material is based upon work supported by the National Science Foundation under Partnerships for International Research and Education (PIRE) Grant No. 0530109 and the Michigan Space Grant Consortium.

I would like to thank my committee members: Dr. Alessandro Tibaldi and Dr. Claudia Corazzato for their time and input in my research. Working with them has been a privilege. Special thanks to my advisor, Dr. Thomas Oommen, for his tireless support and guidance.

Additionally, l'd like to thank my friends for their help in Guatemala collecting data and samples: Patrick Manzoni, Kyle Brill, Justin Olson, Josh Richardson, Jay Wellik, Chet Hopp, Jordan Van Sickle, and Hilary Morgan.

To Dr. William I. Rose, Dr. John S. Gierke, and Dr. Greg Waite for their support of my research.

To Bob Barron, for being my mentor in the lab.

To Rudiger Escobar-Wolf and Miriam Rios for their wisdom and patience.

To Amie Ledgerwood and Kelly McLean for taking care of all the logistics.

To Jamie Holzhuter for the endless support.

And finally, all of my love and admiration to my biggest fans: Mom and Dad. 


\begin{abstract}
The continual eruptive activity, occurrence of an ancestral catastrophic collapse, and inherent geologic features of Pacaya volcano (Guatemala) demands an evaluation of potential collapse hazards. This thesis merges techniques in the field and laboratory for a better rock mass characterization of volcanic slopes and slope stability evaluation. New field geological, structural, rock mechanical and geotechnical data on Pacaya is reported and is integrated with laboratory tests to better define the physical-mechanical rock mass properties. Additionally, this data is used in numerical models for the quantitative evaluation of lateral instability of large sector collapses and shallow landslides. Regional tectonics and local structures indicate that the local stress regime is transtensional, with an ENE-WSW $\sigma 3$ stress component. Aligned features trending NNW-SSE can be considered as an expression of this weakness zone that favors magma upwelling to the surface. Numerical modeling suggests that a large-scale collapse could be triggered by reasonable ranges of magma pressure $(\geq 7.7 \mathrm{MPa}$ if constant along a central dyke) and seismic acceleration ( $\geq 460 \mathrm{~cm} / \mathrm{s} 2$ ), and that a layer of pyroclastic deposits beneath the edifice could have been a factor which controlled the ancestral collapse. Finally, the formation of shear cracks within zones of maximum shear strain could provide conduits for lateral flow, which would account for long lava flows erupted at lower elevations.
\end{abstract}




\section{CHAPTER 1: Unifying Chapter}

\subsection{Introduction}

Volcanoes are exceptional in the fact that they grow. Each time they erupt, they load more material onto their flanks, building themselves taller and wider. Often, this material is loose, heavily fractured, or subjected to hydrothermal alteration. This, in addition to a complex internal magmatic system, causes volcanoes to be inherently unstable. Once considered rare, volcanic collapse is now recognized to be a common process in the evolution of volcanoes (Carrasco-Núñez et al. 2011). The first major collapse observed and scientifically documented was during the 1980 eruption and associated collapse of Mount St. Helens (USA), after which there was a surge of interest in volcanic edifice failure (Voight et al. 1981). Now, more than 400 volcanoes world-wide show evidence of past collapses: over 40 debris avalanches are associated with Quaternary arcs in Central America alone (Siebert et al. 2006).

Among all volcanic hazards, the collapse of a volcanic edifice represents one of the most devastating scenarios threatening nearby populations and infrastructure worldwide; it has been estimated that in the past 400 years, 20,000 people have died in these events (Siebert et al. 1987). Often, they are associated with magmatic or phreatic eruptions, but some have occurred in the absence of volcanic activity. This was the case at Unzen Volcano (Japan), where a collapse was triggered by a nearby $M=6.4$ earthquake that caused more than 15,000 casualties in 1792 ( $\mathrm{Ui}$ et al. 2000). The conditions and precursory events of any given collapse are different and difficult to determine, however by understanding the factors that provoke collapse we can mitigate the loss of life and property more successfully. 


\subsection{Background}

\subsubsection{Volcanic Avalanches and their Hazards}

Although relatively rare events in a human lifetime, volcanic collapses can be extremely deadly. Debris avalanches represent the most catastrophic and hazardous event associated with an edifice collapse, defined by Schuster and Crandell (1984) as rapidly moving, heterogeneous mixtures of unsorted rock and matrix mobilized by gravity. These events can travel at speeds of 50 to $150 \mathrm{~m} / \mathrm{s}$ (Ui et al. 1986; Siebert et al. 1995) containing several cubic kilometers of debris and traveling 10's of kilometers away from the volcano. Pyroclastic density currents from lateral blasts, such as what occurred at Mount St. Helens, are also very deadly events that can travel up to $30 \mathrm{~km}$ away from the source (Siebert et al. 1987). At coastal or oceanic volcanoes, tsunamis caused by a large volume of material sliding into the ocean are serious threats. Of nearly 20,000 casualties related to tsunamis, three-fourths of these originated from volcanic landslides (Carrasco-Núñez et al. 2011). After a slope failure occurs, secondary events such as magmatic eruptions, ash and tephra fall, and lahars can cause further damage and devastation.

\subsubsection{Studying Slope Stability}

Understanding volcanic collapse is an extremely difficult task because of the many triggers; factors that influence slope stability can include gravity (static loading, volcano spreading), water (liquefaction, change in water table), regional and local structures (discontinuity systems, bedding attitude), weak materials (weathering and alteration, changes in the edifice), and triggering events (dike intrusion, seismicity), to name a few (Voight and Elsworth 1997). Additionally, these factors can act in combined processes, further complicating the stability of an edifice.

Volcanic slope stability has been studied using a variety of techniques. Field studies, including the recognition of past collapses, analyzing the diagnostic 
features of volcanic debris avalanches, and performing structural studies is an integral part of defining and characterizing these events (Voight et al. 1981; Siebert 1984; Ui et al. 1986; Ui 1987; Glicken 1991; Ui et al. 2000). Studies have explored several triggers of volcanic slope failure, including hydrothermal alteration (Watters and Delahaut 1995; Zimbelman et al. 2003), geotechnical properties (Watters et al. 2000; Zimbelman et al. 2003), gas pressure (Voight and Elsworth 2000), magma induced seismicity (Elsworth and Voight 1995), and edifice deformation (Donnadieu and Merle 1998; Donnadieu et al. 2001).

Standard engineering methodologies for studying non-volcanic slopes using geomechanical models have recently been borrowed for studying volcanic slopes (Voight 2000). These include applying Limit Equilibrium Methods (LEM) (Voight et al. 1983; Iverson 1995; Elsworth and Voight 1996; Voight and Elsworth 1997; Elsworth and Day 1999; Hurlimann et al. 2000; Reid et al. 2000; Donnadieu et al. 2001) and numerical modeling by Distinct Element Methods (DEM) (Zimbelman et al. 2004), Finite Difference Methods (FDM) (Hurlimann et al. 2000; Apuani et al. 2005a, b) and Finite Element Methods (FEM) (Sousa and Voight 1995). However, numerical data on the relevant mechanical properties remains a major source of uncertainty due to the lack of direct measurements (Thomas et al. 2004; del Potro and Hürlimann 2008). Strength values used in these analyses are uncertain due to unknown interior makeup and geometry, inaccessible locations of volcanic rock masses, and the diversity of materials that compose volcanoes (del Potro and Hürlimann 2008).

The methodology used in this study is a combined approach of structural and geomechanical field studies, and morphometric analysis. Additionally, slope stability is assessed with Limit Equilibrium Methods (LEM) and stress-strain numerical modeling with Finite Element Methods (FEM) which has been shown to have enormous potential for understanding volcano collapse mechanisms associated with deep-seated failures (Sousa and Voight 1995; Apuani et al. 2005b; Apuani and Corazzato 2009). This study can better determine whether a 
multi-dimensional methodology such as this is appropriate for complex volcanic slope stability problems.

\subsubsection{The Example of Pacaya Volcano}

Pacaya is an active stratovolcano located $30 \mathrm{~km}$ south of Guatemala City, Guatemala. A large $\left(0.65 \mathrm{~km}^{3}\right)$ sector collapse of the volcano occurred $0.4-2 \mathrm{ka}$ B.P., producing a debris avalanche that traveled $25 \mathrm{~km} \mathrm{S-SW}$ of the edifice (Fig. 1-1) (Vallance et al. 1995). The current Mackenney cone has since rebuilt within the scarp of this ancestral collapse (Fig. 1-2). In addition to a large ancestral collapse, several other factors can be considered potentially hazardous to the edifice's stability. Since the renewal of activity in 1961, the volcano has loaded 100 to $150 \mathrm{~m}$ of lava flow and tephra material preferentially on the SW flank of the cone, causing the cone to grow asymmetrically. This, in addition to a general slope between Guatemala's highlands and the coastal plain (Vallance et al. 1995) contribute to an asymmetrical and therefore less stable cone.

Another factor is the recent coincident summit Strombolian eruptions, collapse features, and flank lava eruptions that suggest the possibility of magma reservoirs high in the cone, an idea that has been hypothesized previously (Eggers 1983; Vallance et al. 1995; Matías Gómez 2009). A shallow magma chamber could be an influencing factor in recent collapses, the first of which occurred in 1962 when an oval-shaped area subsided near the summit, coinciding with a long lava flow from a vent at the base of the cone. This depression has since been filled with material from later eruptions. During eruptions in May 2010, a second collapse occurred when a linear trough developed on the NW side of the cone during eruptive activity. This trough, which extends $600 \mathrm{~m}$ from the summit, appeared only a few days before a long lava flow was produced from a vent at the base of the cone outside of the ancestral collapse scarp. Finally, a thick sequence of tephra and ignimbrite pyroclastics erupted from the nearby Amatitlán caldera covers the region and is thought to 


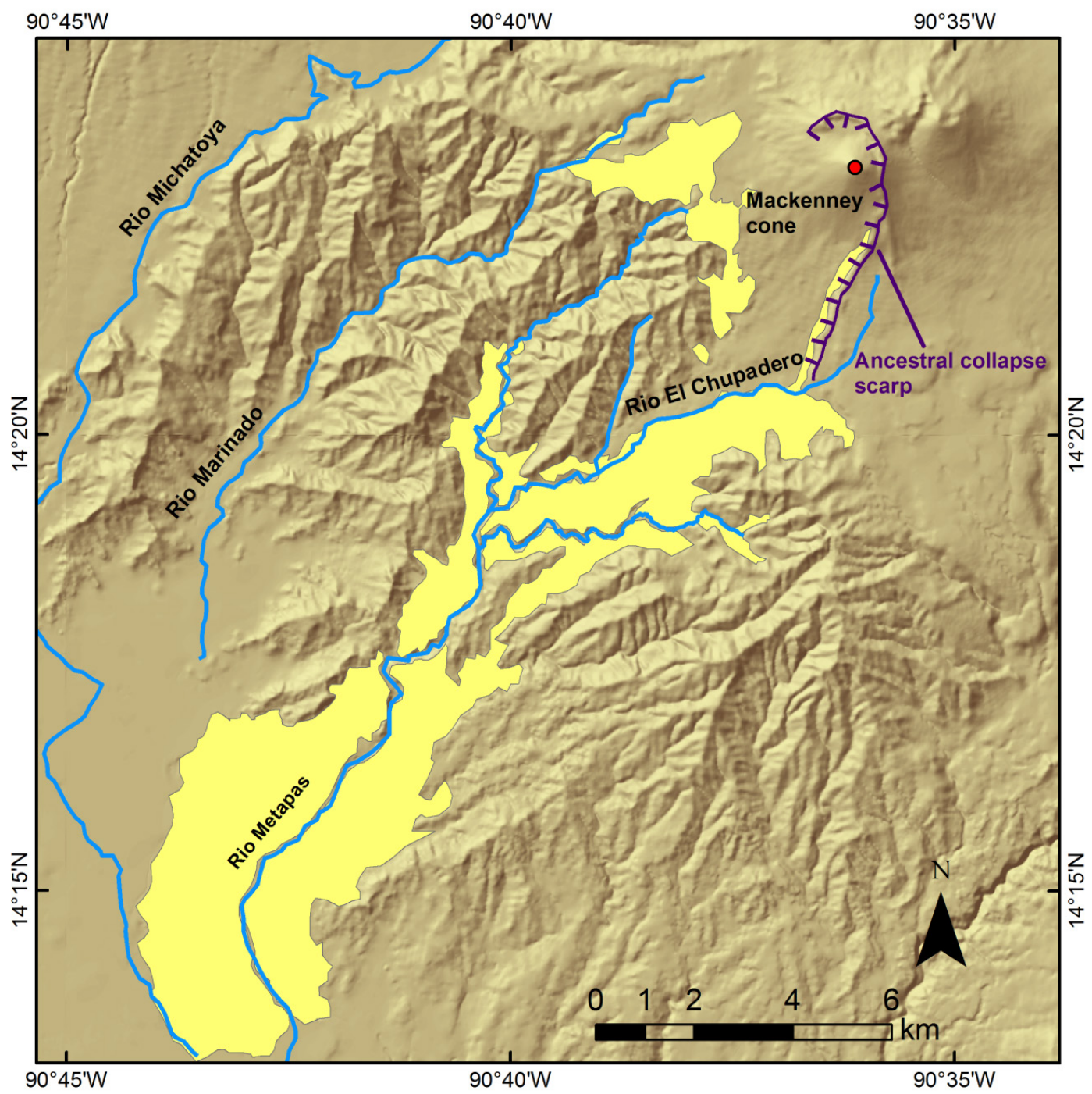

Figure 1-1 Extent of the debris avalanche deposit (in yellow) from the ancestral collapse, which traveled $25 \mathrm{~km}$ to the SW. Modified from Vallance et al. (1995).

exist beneath the edifice (Eggers 1972; Wunderman and Rose 1984; Vallance et al. 1995). Studies of the ancestral debris avalanche have found large blocks of white, fibrous, biotite-bearing pumice (Fig. 1-3) (Vallance et al. 1995). This pumice likely originated from deep parts of the original avalanche mass from the layer of pyroclastics. Although some was likely removed with the ancestral collapse, recent eruption deposits still contain pieces of this layer, suggesting that Pacaya is still sitting on a bed of pyroclastics. Considering all of these 


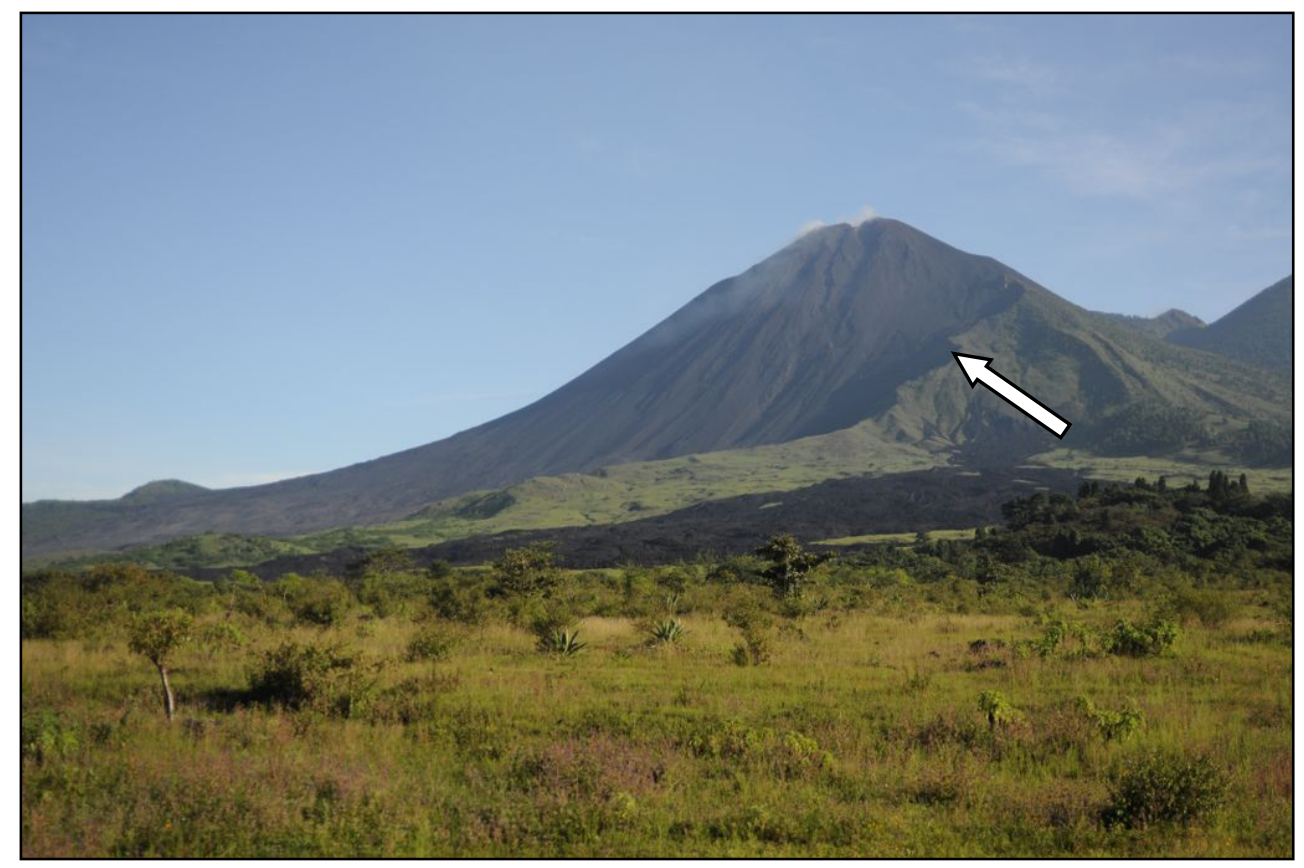

Figure 1-2 Pacaya volcano looking to the NW, with arrow pointing to the ancestral collapse scarp.

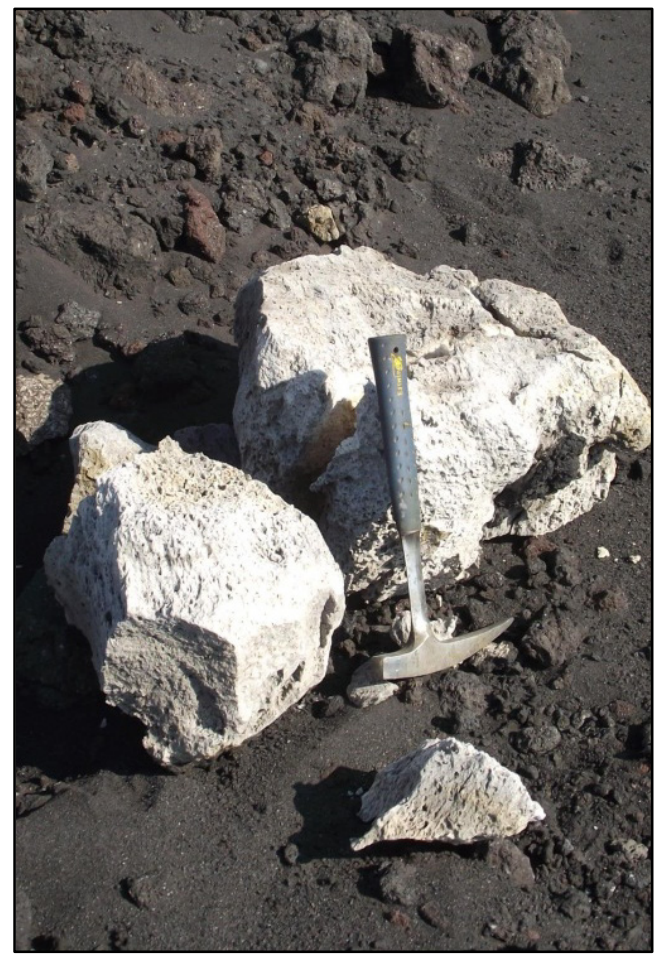

Figure 1-3 Pieces of the tephra and ignimbrite pyroclastics erupted from the nearby Amatitlán caldera are brought up in current eruptions. 
destabilizing factors, one of the biggest concerns at Pacaya is related to another large lateral collapse of the active cone. Given that volcanoes have been shown to repeat lateral collapse events (Tibaldi and Lagmay 2006 and references therein) and that Pacaya is surrounded by several communities totaling about 9000 people that live less than $5 \mathrm{~km}$ from the active cone (Matías Gómez 2009), it is critical to analyze the stability of the cone for hazard assessment.

\subsection{Objectives}

The aim of this research is to better understand slope failure hazards at volcanoes through the example of Pacaya Volcano in Guatemala. This will include:

(i) Making predictions of the most plausible orientation of lateral failures through structural and morphometric analysis, and considering the previous geological history;

(ii) Determining the physical-mechanical material properties of Pacaya's intact rocks and rock masses through field surveys and laboratory testing;

(iii) Developing a geotechnical model of the volcano;

(iv) Understanding the mechanisms and destabilizing factors that could lead to a large-scale collapse with the use of Limit Equilibrium and Finite Element Methods.

Detailed field and laboratory data are presented in the second chapter (Geotechnical Data). The results of this work are presented in a technical paper, prepared for submission to the Bulletin of Volcanology (Core Paper).

\subsection{Major Findings of Technical Work}

In this paper, the slope stability of the active Pacaya Volcano was studied by means of field and laboratory data, integrated to produce the best available $2 \mathrm{D}$ numerical model of the cone. A geomechanical model was developed based on the physical-mechanical material properties of Pacaya's intact rocks and rock 
mass characteristics found through field observations and laboratory tests. The Hoek and Brown failure criterion was used to calculate the rock mass friction angle, apparent cohesion, and rock mass parameters in a specified stress range. Several situations were assessed using the Limit Equilibrium Method (LEM) and Finite Element Method (FEM) using Rocscience software Slide 6.0 and Phase2 8.0 (Rocscience 2011) to constrain various destabilizing processes. These include static conditions (under gravity forces only), and considering the application of magma and seismic pressure as triggering mechanisms.

The results of the structural study reveal the presence of a series of $\mathrm{N}$ and NWstriking discontinuities which are parallel to regional structures, suggesting that Pacaya is controlled by regional tectonics. This, paired with the orientation of features on the cone in a NNW-SSE pattern, suggest a transtensional stress regime at Pacaya, with an E-W to ENE-WSW $\sigma_{3}$. If we take into consideration all the aforementioned features, the previous history of the volcano, the orientation and location of the volcanic rift zone, the general N-S direction of regional slope, and the regional/local stress patterns, the most likely direction of a future collapse is aligned roughly SW. Past history of edifice sector collapse to the SW, the structurally weak zone oriented NNW-SSE, and the recent lava piling suggest the SW flank could fail again in the future.

Results from modeling indicate that the edifice remains stable under gravity alone, but that a large-scale collapse could be triggered by reasonable ranges of magma pressure $\left(\geq 7.7 \mathrm{MPa}\right.$ along a dike) or seismic acceleration $\left(\geq 460 \mathrm{~cm} / \mathrm{s}^{2}\right.$ peak ground acceleration). Based on the geometry of the affected material, pyroclastic deposits beneath the edifice could have been a factor that controlled the ancestral collapse. Numerical modeling results are concordant with those from LEM and reveal that zones of maximum shear strain could provide flow conduits for lateral flow, which would account for the long lava flows erupted at lower elevations. 


\subsection{Conclusions}

Slope instability phenomena are very complex in volcanic environments. Volcanoes are typically heterogeneous, with complex plumbing magmatic systems and frequent changes in morphology. Because of this, several assumptions and simplifications have been made in previous works and also in this research, including the geotechnical model's geometry and the characteristics and behavior of the magma system. These simplifications are reasonable and fit the purpose of this conceptual modeling.

It is difficult to find modeling tools capable of addressing complicated volcanic environments, especially when a multidisciplinary approach is used. Although modeling does not provide exact solutions to slope stability problems, this study has shown that the combined use of LEM and FEM analyses give important insights into possible collapse scenarios and the likely mechanisms involved in these circumstances.

Further improvements could include more extensive field work to collect more information on fracture and joint orientation, rock mass characterization, and rock strength parameters to assure a normal distribution of these characteristics. This is especially true for pyroclastic deposits at Pacaya, which were not measured in this study. These pyroclastics and other hydrothermally altered material likely make up a large portion of the cone at higher elevations (Vallance et al. 1995), which could further destabilize the edifice.

Future work could also consider the comparison of $2 \mathrm{D}$ with $3 \mathrm{D}$ computational modeling, and computational modeling with GPS or InSAR deformation data which are both available for Pacaya. By mimicking deformation seen in real data with computational models, internal magmatic processes could be better constrained. Additionally, this data could determine the primary mechanisms of collapse events and could be used to validate or invalidate the existing models. 


\section{CHAPTER 2: Geotechnical Data}

\subsection{Rock mass strength and elastic properties}

Rock mass strength was evaluated using Hoek and Brown's non-linear strength law (Hoek 1994). The parameters involved in the analysis include: uniaxial compressive streng th of the rock mass $\left(\sigma_{c \mathrm{i}}\right)$; material constant $\left(m_{i}\right)$ that describes the petrology and texture of the intact rock; a visual description of the structure and surface conditions of the rock mass based on the Geological Strength Index (GSI); and the disturbance factor $(D)$ which is a numerical value of the degree of disturbance to which the rock mass has been subjected by blast damage, varying from zero (no disturbance) to unity (most disrupted). This disturbance factor originated from experience in the design of slopes in large mines, where the Hoek-Brown criterion tended to be over-optimistic in estimating rock mass properties. It is still unclear how to characterize volcanic rock masses in terms of $D$ (Thomas et al. 2004), therefore this study uses $D=0$ in considering the entire rock mass. The ranges and values used as input data for numerical modeling represent the predominate values found through field observations and laboratory tests (described below).

The Hoek and Brown failure criterion for jointed rock masses has the form:

$$
\sigma_{1}^{\prime}=\sigma_{3}^{\prime}+\sigma_{c i}\left(m_{b} \cdot \frac{\sigma_{1}^{\prime}}{\sigma_{c i}}+s\right)^{a}
$$

where $\sigma_{1}^{\prime}$ and $\sigma_{3}^{\prime}$ are the maximum and minimum effective stresses at failure, $\sigma_{c i}^{\prime}$ is the uniaxial compressive strength of the intact rock, $s$ and $a$ are constants that depend upon joint conditions and the degree of fracturing for the rock mass, and $m_{b}$ is a reduced material constant for the rock mass expressed as:

$$
m_{b}=m_{i} \exp \left(\frac{G S I-100}{28-14 D}\right)
$$


The physical-mechanical properties include both the Hoek-Brown rock mass properties necessary for the failure criterion and the calculated Mohr-Coulomb rock mass equivalent parameters that are typically used for LEM and FEM analysis. The generalized Mohr-Coulomb criterion describes a linear relationship between normal and shear stresses at failure and is described by:

$$
T=\sigma \times \tan \varphi+\mathrm{C}
$$

where $T$ is the shear strength, $\sigma$ is the normal stress, $c$ is the intercept of the failure envelope with the $\tau$ axis, and $\varphi$ is the slope of the failure envelope. The Mohr-Coulomb parameters were calculated using RocLab 1.0 (Rocscience 2011). In converting the Hoek-Brown to equivalent Mohr-Coulomb parameters, it is necessary to specify a range for the upper limit of confining stress $\left(\sigma^{\prime}{ }_{3 \max }\right)$ (Hoek et al. 2002). For Pacaya, this was calculated using Phase2 8.0 code (Rocscience 2011) using an empirical relationship considering the height of the slope and the unit weight of the rock mass, resulting in a range of $\sigma_{3 \max }^{\prime}=5-15$ $\mathrm{MPa}$. This is representative of the extent of the model at depth.

\subsection{Physical and mechanical properties of in tact rock and discontinuities}

To input lithotechnical unit properties for numerical analyses, the intact rock and rock mass parameters must be described in accordance with engineering material properties. Previous studies carried out at Pacaya considered only lithological and petrological descriptions, neglecting geotechnical characteristics of the rock masses. Therefore, this study carried out geotechnical and structural surveys along the old collapse scarp where outcrops were available (Fig. 2-1). The exact location of the sites are listed in Table 2-1.

\subsubsection{Physical properties}

Pacaya's main edifice is made up of a sequence of lava flows, brecciated lava, scoria and tephra layers, and pyroclastics. The lavas are porphyritic dark grey to light grey basalt with olivine and plagioclase phenocrysts (up to $45 \%$ ) and 
microphenocrysts, and minor clinopyroxene and magnetite microphenocrysts (Bardinezteff and Deniel 1992; Conway 1995; Matías Gómez et al. 2012). There are no significant petrographic differences between the prehistoric, historic, and modern lavas (Eggers 1972). The lavas represent the strongest geotechnical class and are geochemically monotonous, with $\mathrm{SiO}_{2}$ between 50 and 52.5 wt\% and $\mathrm{MgO}$ between 3 and 5 wt\% (Matías Gómez et al. 2012).

Breccia rocks at Pacaya are primarily autoclastic breccias which form the carapace and base of "a'a" flows that form during lava flow cooling. The vesicular

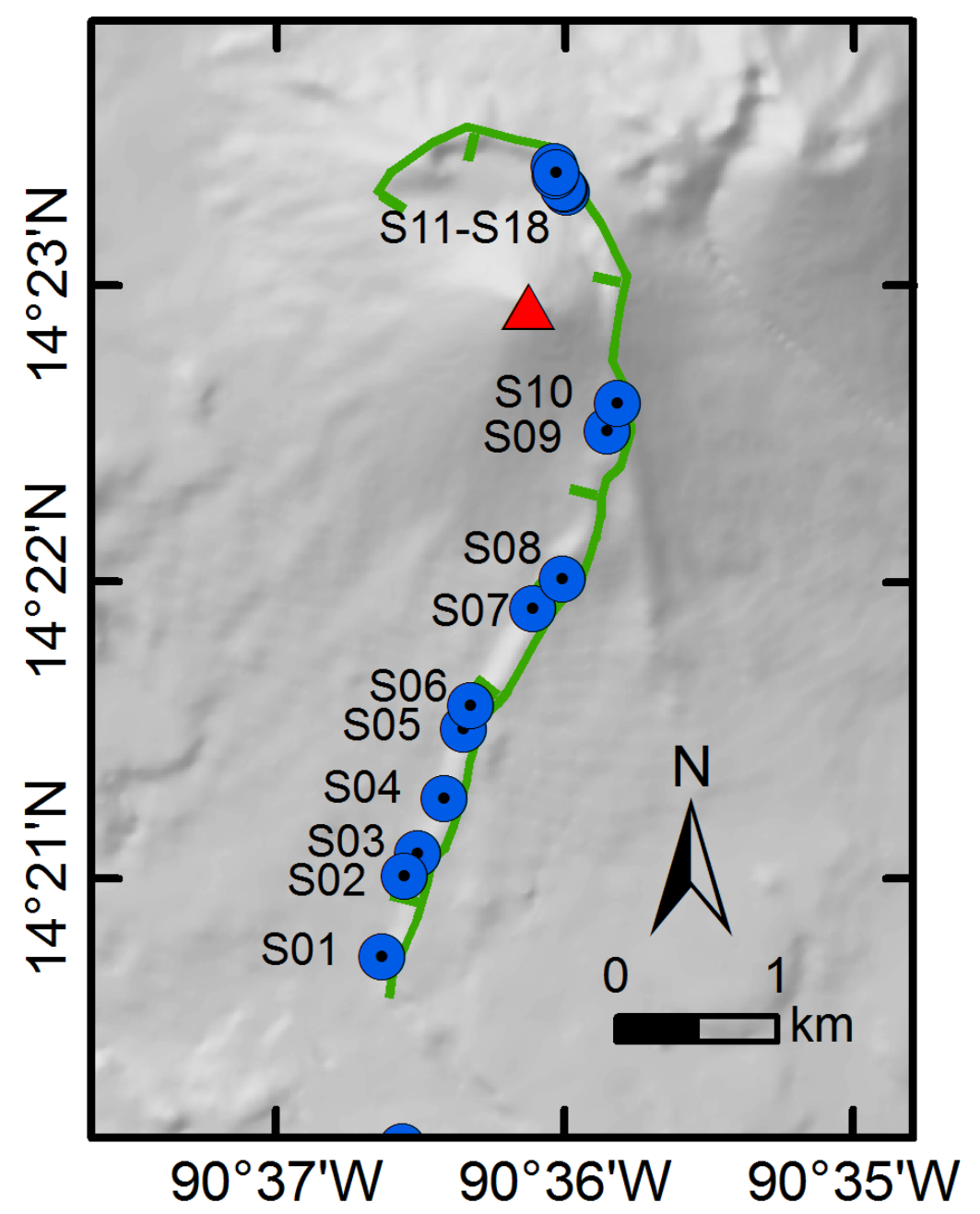

Figure 2-1 Location of geotechnical surveys along Pacaya's scarp marked with dotted circles. The main volcanic vent (Mackenney cone) is noted with a triangle. 
Table 2-1

Description of geotechnical survey sites, including the altitude and GPS coordinates.

\begin{tabular}{llll}
\hline Site & Location & Altitude & GPS \\
\hline S01 & scarp & 1223 & 15P 0757707E, 1586932N \\
\hline S02 & scarp & 1306 & 15P 0757895E, 1587717N \\
\hline S03 & cone & 2275 & 15P 0759110E, 1590606N \\
S04 & cone & 2237 & 15P 0759110E, 1590554N \\
S05 & scarp & 1306 & 15P 0757952E, 1587772N \\
\hline S06 & scarp & 1614 & 15P 0758798E, 1589513N \\
S07 & scarp & 1612 & 15P 0758593E, 1589269N \\
\hline S08 & scarp & 1460 & 15P 0758330E, 1588734N \\
\hline S09 & scarp & 1488 & 15P 0758225E, 1588632N \\
\hline S10 & scarp & 1431 & 15P 0758110E, 1588206N \\
\hline S11 & valley & 1250 & 15P 0756215E, 1588139N \\
\hline S12 & cone & 2253 & 15P 0758813E, 1592053N \\
\hline S13 & cone & 2305 & 15P 0758799E, 1592070N \\
\hline S14 & cone & 2314 & 15P 0758799E, 1592073N \\
\hline S15 & cone & 2303 & 15P 0758792E, 1592080N \\
\hline S16 & cone & 2303 & 15P 0758792E, 1592080N \\
\hline S17 & cone & 2285 & 15P 0758742E, 1592153N \\
\hline S18 & cone & 2282 & 15P 0758742E, 1592153N \\
\hline & & &
\end{tabular}

rocks are composed of angular to sub-angular densely interlocking clasts. They tend to be dark grey and are petrographically and geochemically the same as the lava rocks.

The lithology of the pyroclastics at Pacaya include air fall, unwelded ash-flow, tephra and bomb fall deposits, ignimbrites, and volcaniclastic deposits reworked by secondary processes. Matías Gómez et al. (2012) reported and mapped 87 significant tephra dispersion events from 1961-2010 alone. A distinct layer of 
pyroclastics exists in the ancestral avalanche deposit, which is unconsolidated and unsorted dacitic pumice (Vallance et al. 1995). This thick biotite-bearing layer is white and fibrous and contains inclusions of andesite, basalt, and dacite in an ashy matrix (Eggers 1972; Vallance et al. 1995). It is likely derived from a tephra and ignimbrite sequence that draped the landscape prior to the formation of the pre-avalanche Pacaya, which varies from 5 to $200 \mathrm{~m}$ across the region (Eggers 1972) and can still be seen in outcrops around the volcano (Fig. 2-2, Pyroclastics). Although some of this layer was likely removed with the ancestral collapse, recent eruption deposits still contain pieces of this layer (Fig. 1-3), suggesting that Pacaya is still sitting on a thick bed of pyroclastics.

\subsubsection{Lithotechnical units}

For numerical modeling purposes, geological units can be simplified and categorized into lithotechnical units according to their mechanical characteristics, based on field observations and geological maps. At Pacaya, the rock mass can be grouped into:

(i) Lava (L): predominately lava $(>70 \%)$ alternating with autoclastic breccia layers;

(ii) Lava + Breccia (LB): alternating lava (40-70\%) and breccia layers;

(iii) Breccia (B): predominately autoclastic breccia alternating with lava layers $(<40 \%)$; and

(iv) Pyroclastics $(\mathrm{P})$ : prevailing pyroclastics,

as shown in Fig. 2-2. Along the scarp, an alternating pattern of lava and breccia rocks can be projected and used as a good indication of the interior stratigraphy of the volcano. As described above, Pacaya has been characterized by other authors as having more or less the same geochemical and petrologic properties throughout its growth (Eggers 1972; Walker 1989; Bardinezteff and Deniel 1992; Vallance et al. 1995). To simplify the edifice for modeling purposes, the rock mass can be represented by the most prevalent percentage of lava to breccia in 
the studied outcrops, which was the alternating lava (40-70\%) and breccia lithotechnical unit LB. The rock mass properties for this unit are uniform, representing an intermediate value of lava and breccia rocks found through geomechanical surveys and tests performed along the collapse scarp (locations, Fig. 2-1). While the material properties undoubtedly vary throughout this unit due to rock and structural heterogeneity, the small volume, random distribution, and lack of continuity of individual units requires strong assumptions. Therefore, a simplification of this rock mass is necessary and fits the purpose of this conceptual modeling.
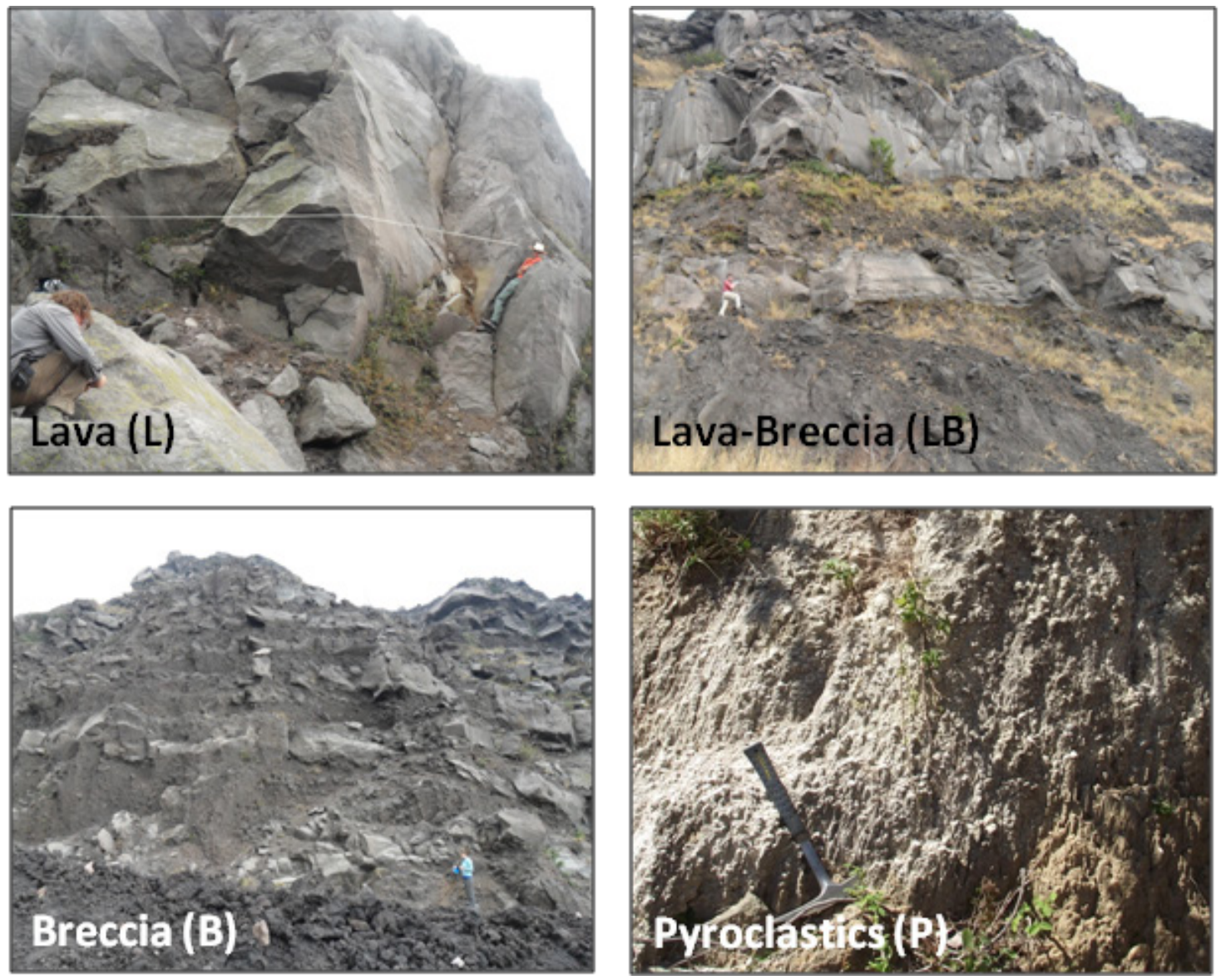

Figure 2-2 Lithotechnical units at Pacaya. For modeling, the major rock mass of the edifice was represented by an alternating lava (40-70\%) and breccia sequence (LB). 


\subsubsection{Quantitative description of rock masses and discontinuities}

Classification and characterization of the rock mass and discontinuities were conducted at 10 field sites (sites S1-S10, Fig. 2-1) based on International Society for Rock Mechanics (ISRM) procedures (ISRM 1981). The properties of discontinuities are used as an initial review of stability conditions of a site, as they can act as potential failure planes and generally weaken the rock mass. Surveys at each site included identifying the number of joint sets and their representative orientations, geometry of the joints (strike, dip, and inclination), spacing of the joints, type of movement, amount of dilation, degree of alteration, roughness coefficient, and presence and nature of infill as described in Wyllie and Mah (2004). These parameters were only found for lava rock, as it is often impossible to identify and describe discontinuities in disintegrated or highly weathered rocks.

To recognize patterns in the joint systems, joints from all of the outcrops were grouped into four sets based on dip/dip direction (Fig. 2-3). The spacing of the joints was determined using a scan-line approach in which the number of joints and distance between each joint is determined in a chosen vertical and horizontal orientation (Fig. 2-4). The strike directions of the main discontinuities at each site are shown in Appendix A.

The roughness of the joints was determined using a comb profilometer and the Joint Roughness Coefficient. The opening of each joint was measured and the infill of each joint was described, including whether there was any alteration of the joint cavity or water present. The directional length and immersion of the joints was measured, and the persistence was noted, which is a measure of the continuous length or area of the discontinuities within a plane. Both the

persistence length $(\mathrm{Pl})$ and persistence area $(\mathrm{Pa})$ were crudely quantified by observing the discontinuity trace lengths on the surface of exposures. The persistence was measures to its termination, which were also classified based on how the joints ended. "Ta" indicates a discontinuity which terminates at the edge 


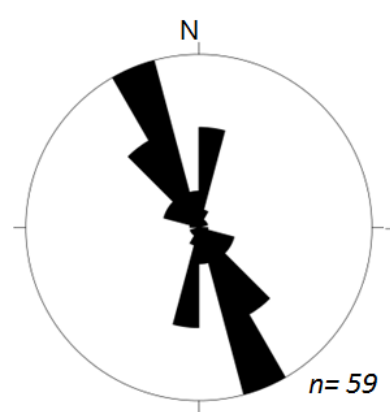

$\mathrm{K} 1$

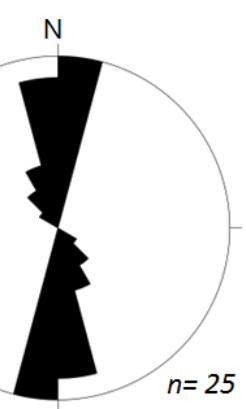

$\mathrm{K} 2$

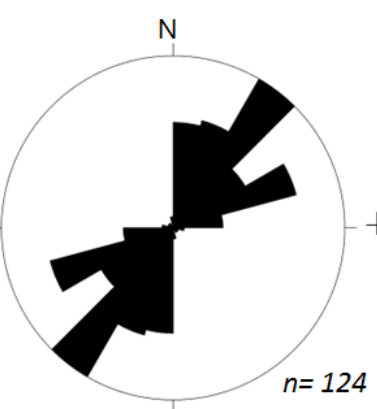

K3

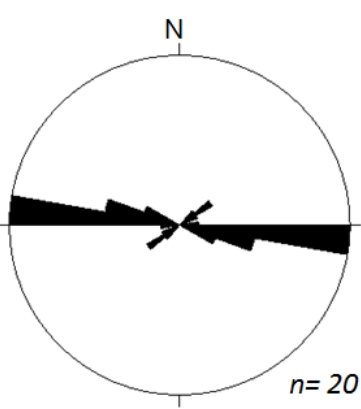

K4

Figure 2-3 Joints from all the outcrops were grouped into four sets to recognize patterns in the join systems.

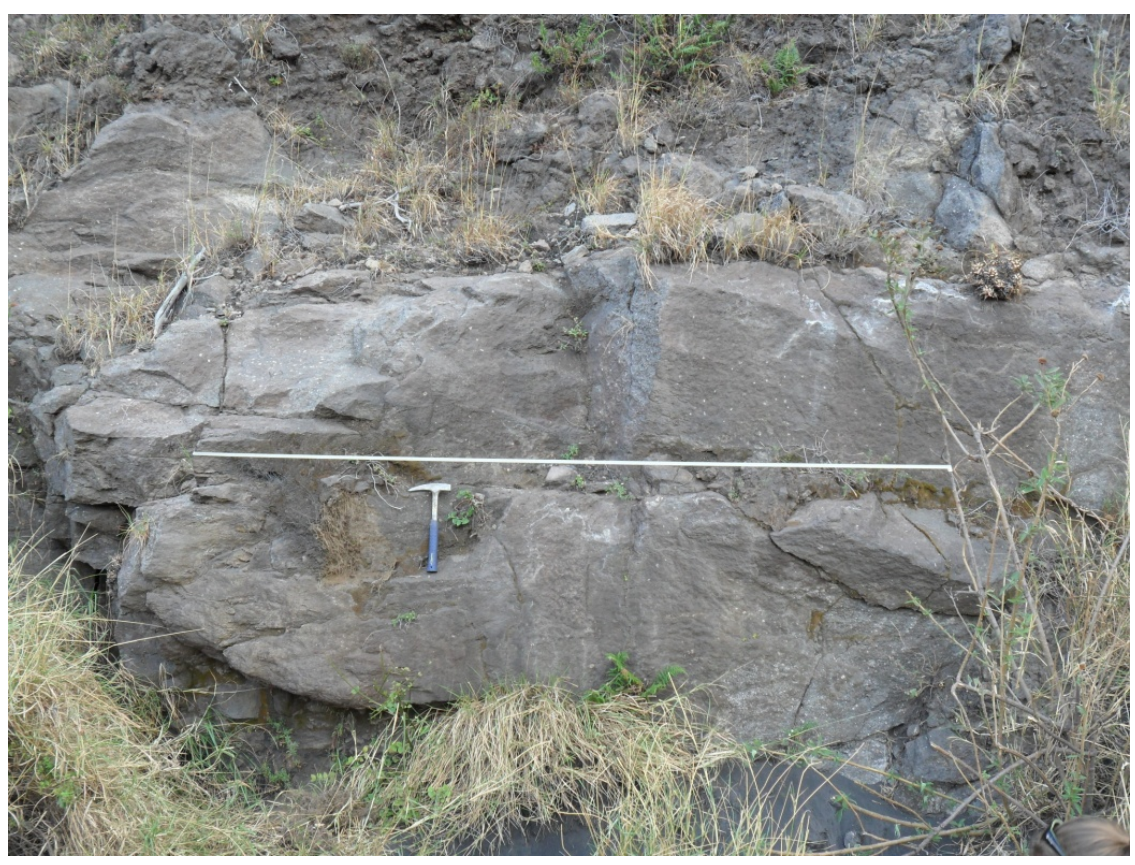

Figure 2-4 A horizontal segment using the scan-line approach.

of the outcrop, "Td" indicates a discontinuity that terminates against another discontinuity, "Tr" indicates a discontinuity which ends against another rock, and "Tx" indicates a discontinuity that ends within the rock. Appendix B lists the geotechnical descriptions of each site.

The parameters described above are necessary for the application of the Rock Mass Rating (RMR) classification, a traditional engineering description of rock 
mass strength developed by Bieniawski (1989). The RMR results for the lava rock of each outcrop analyzed are summarized in Table 2-2 and were converted to equivalent Hoek-Brown rock strength parameters for comparison. Because the rock mass "quality" at Pacaya ranges from poor to very good (i.e. non-indurated pyroclastics versus lava rocks), the rocks of poor quality were impossible to describe using this system. To characterize and evaluate the geomechanical quality of the large variety of rock mass types found at Pacaya, this study instead adopted the GSI introduced by Hoek (1994) and developed by Marinos and Hoek (2000), to describe the rock mass using other Hoek and Brown criterion parameters as described in section 2.1. This is why RMR parameters were not found for sites S11-S18, which were visited during the second field excursion in 2012.

The GSI uses visual characterizations of the rock mass structure and discontinuity surface condition and, when combined with intact rock properties, can be used to extrapolate the rock mass strength and deformability parameters by applying the Hoek-Brown failure criterion. Using GSI, the LB unit was characterized as having good to fair surface quality and slightly disturbed structural integrity (GSI value of 40-60). The other lithotechnical units are shown for comparison, with $L$ having the highest GSI range of 55-70, and $B(30-45)$ and $P(8-20)$ degrading in surface quality and structural integrity (Fig. 2-5).

\subsubsection{Schmidt Hammer tests}

An addition parameter necessary for the Hoek-Brown criterion is the intact rock strength, which was measured in the field using a Schmidt hammer (Fig. 2-6). The Schmidt hammer measures the rebound of a spring-loaded mass impacting against the surface of the sample. The test hammer will hit the concrete at a defined energy and its rebound is dependent on the hardness of the sample. The test was repeated 20 times at each survey site and an average value was taken. These values were converted to equivalent uniaxial compressive strength $\left(\sigma_{\mathrm{ci}}\right)$ values using the following empirical correlation: 


$$
\sigma_{c i}=2.75 \cdot(N-36.83)
$$

obtained exclusively from testing volcanic rocks (Dinçer et al. 2004), with $N$ being the Schmidt hammer rebound value. Using this relation, the uniaxial compressive strength is $88.03 \pm 29.92 \mathrm{MPa}$ for lava rock (reported as average \pm standard deviation) and 47.6 $\pm 11.97 \mathrm{MPa}$ for breccia (averaged site results, Table 2-2).

\subsubsection{Laboratory tests}

Two intact rock samples, one lava and one breccia, were collected from the collapse scarp at sites S08 and S09. Samples were cored in the lab with a length-diameter ratio between 2 and 2.5 based on ASTM standards (ASTM 2000), resulting in 12 lava and 17 breccia cores. Uniaxial compressive strength, bulk volume, and density tests were carried out in the laboratory on these cores. Uniaxial compressive strength tests were conducted using the Material Testing System MTS 810. Unit weight and density tests were performed using displacement tests in a GEOPYC 1360, which works by immersing the rock cores into a dry, solid medium of much smaller particles and then compacting the unit. This compaction consolidates the particles but does not invade the pore space of the sample. The density envelope can then be measured by finding the difference in the distance the piston penetrates the cylinder during the test and the distance the cylinder penetrates during the baseline procedure without the core. This test was performed five times for each core. Unit weight $(\mathrm{V})$ values averaged $26.82 \mathrm{kN} / \mathrm{m}^{3}$ for lava rock (Table 2-3) and $22.92 \mathrm{kN} / \mathrm{m}^{3}$ for breccia rock (Table 2-4).

Laboratory results of compressive strength values tended to be lower than those obtained using the Schmidt hammer, with lava rock being 47.62 $\pm 16.01 \mathrm{MPa}$ (Table 2-3) and breccia being 33.08 $\pm 11.26 \mathrm{MPa}$ (Table 2-4). This pattern is similar to those found by other authors (del Potro and Hürlimann 2008) and could possibly be attributed to vesicularity or small number of samples tested. 


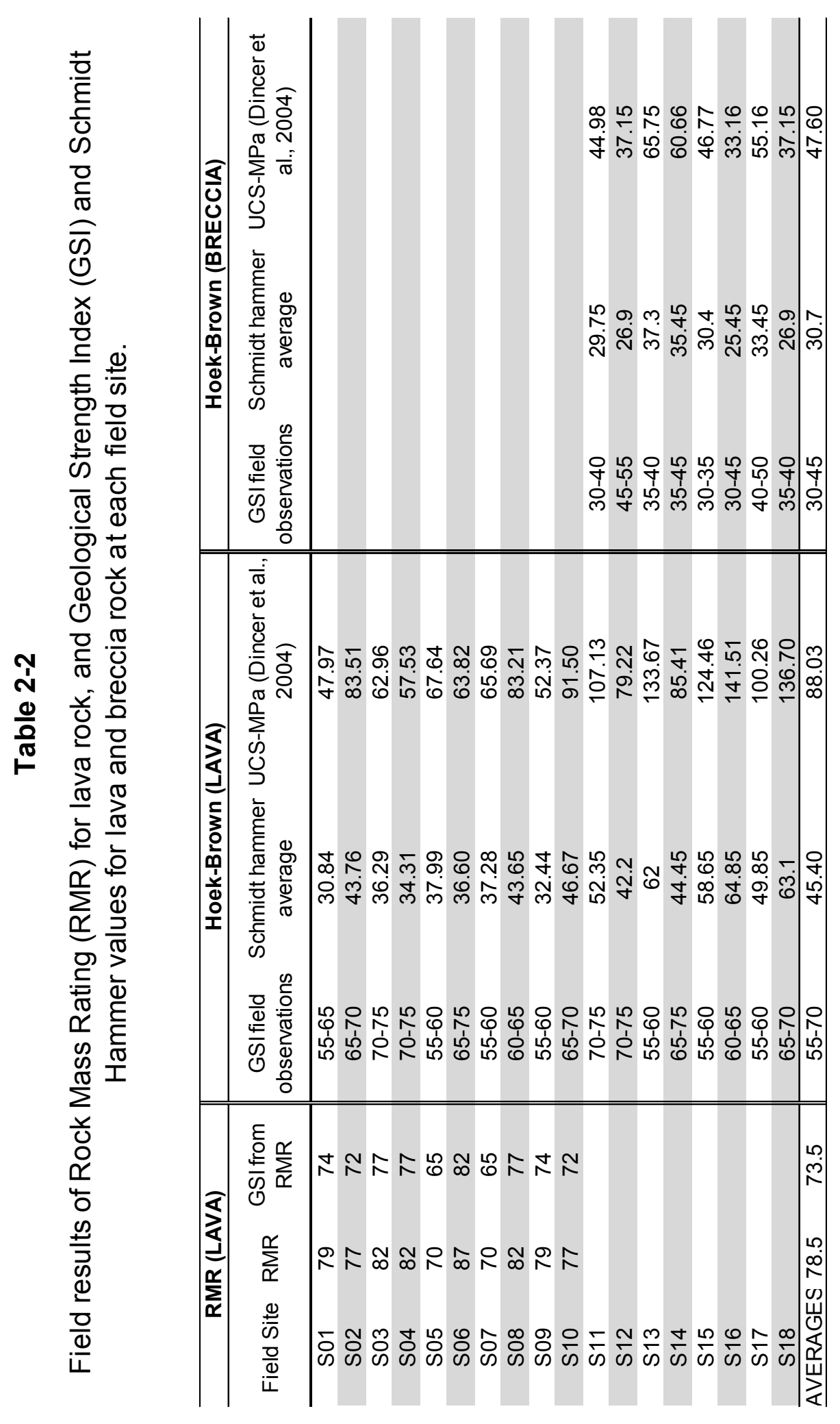




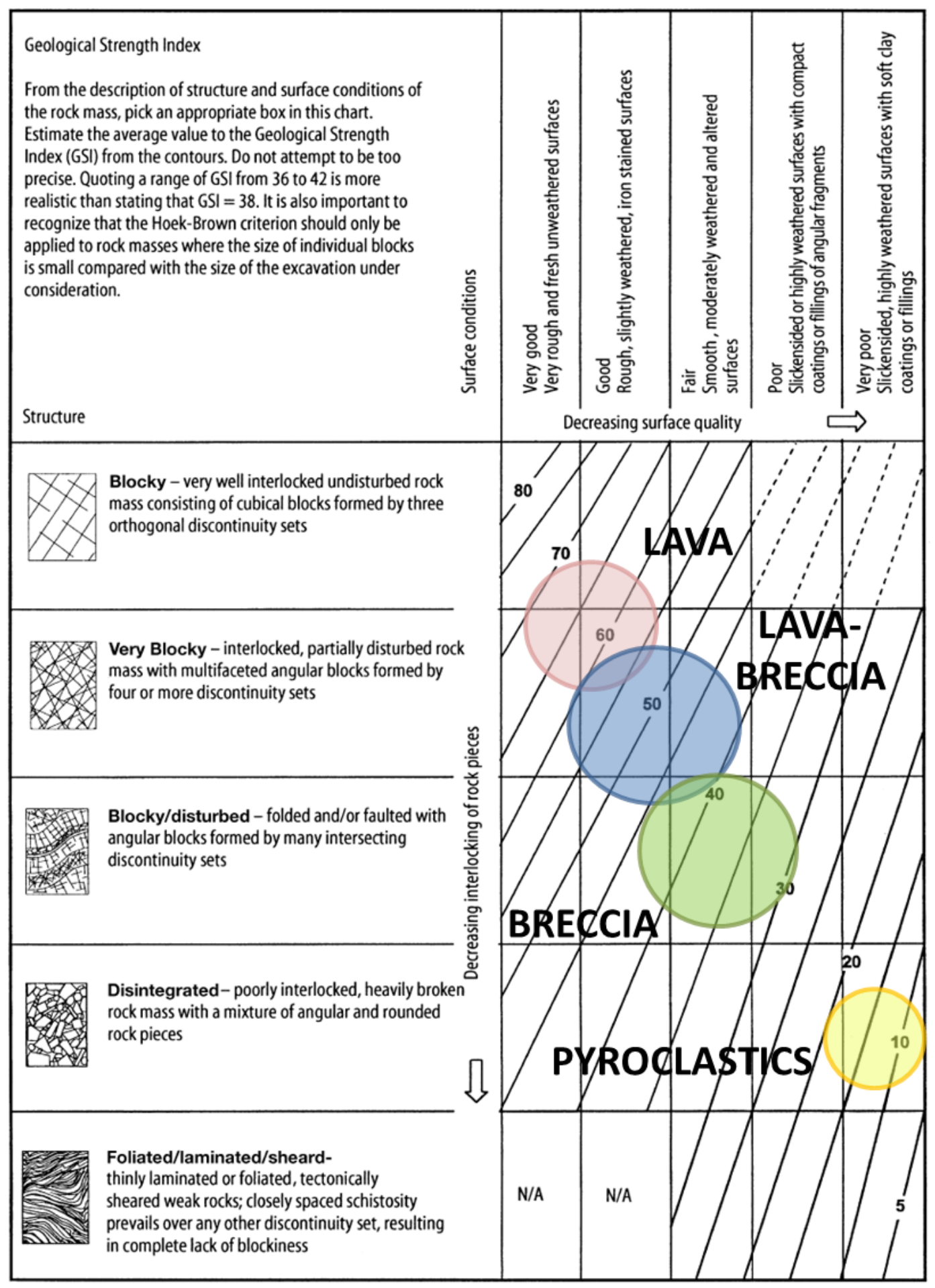

Figure 2-5 Geological Strength Index (GSI) classification of the different lithotechnical units. Classification table modified from Marinos and Hoek (2000). 


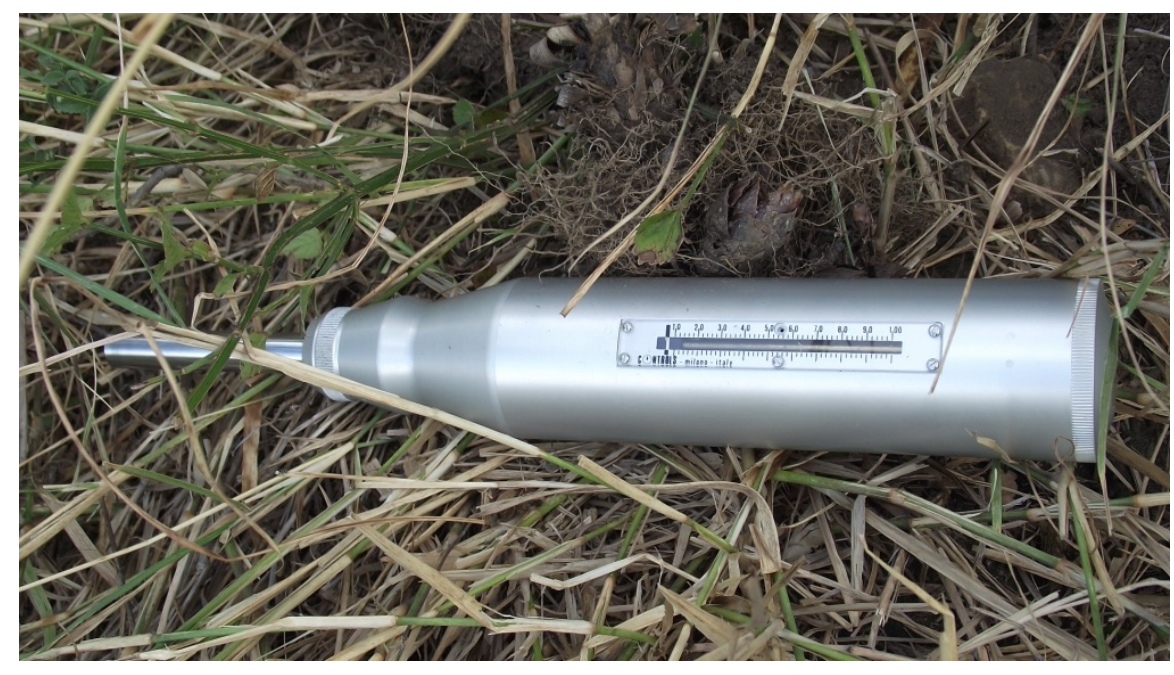

Figure 2-6 The Schmidt hammer measures intact rock strength in the field. 


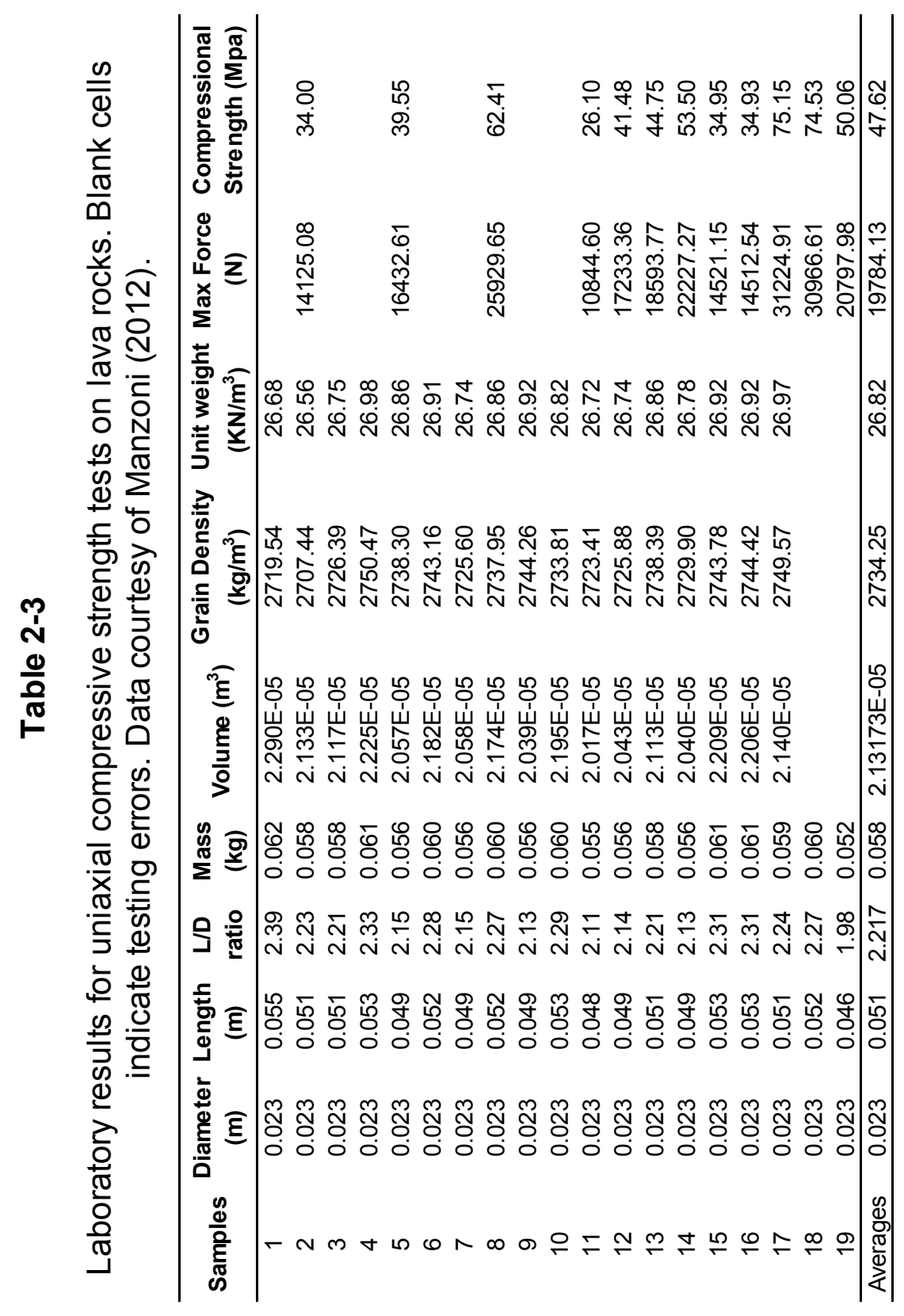




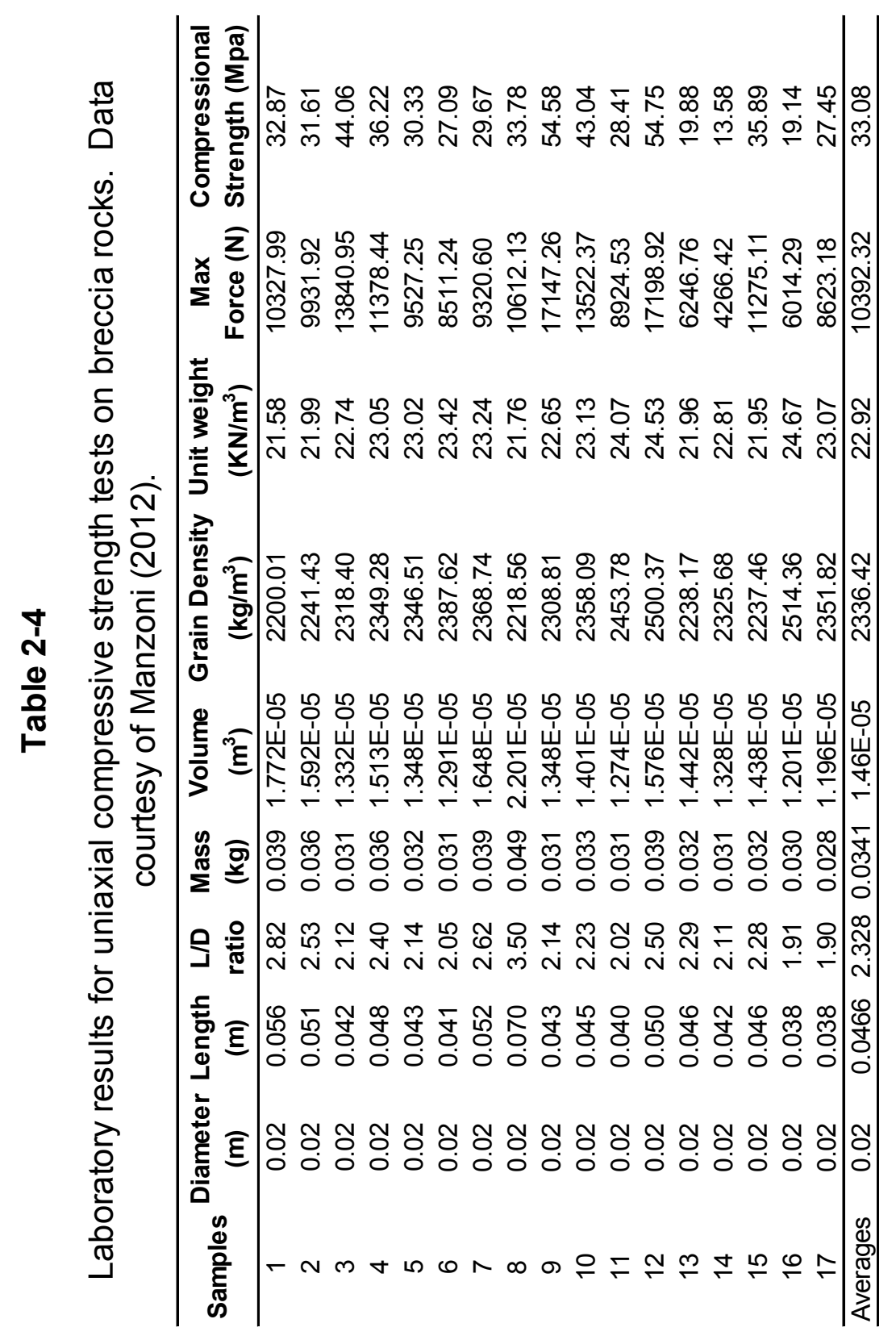




\title{
CHAPTER 3: Core Paper*
}

\section{An integrated field-numerical approach to assess slope stability hazards at volcanoes: the example of Pacaya, Guatemala}

\author{
Lauren N. Schaefer ${ }^{1}$, Thomas Oommen ${ }^{1}$, Claudia Corazzato ${ }^{2}$, Alessandro \\ Tibaldi $^{2}$, Rudiger Escobar-Wolf ${ }^{1}$, and William I. Rose Jr. ${ }^{1}$ \\ ${ }^{1}$ Department of Geological and Mining Engineering and Sciences, Michigan \\ Technological University, Houghton, MI, USA
${ }^{2}$ Dipartimento di Scienze dell'Ambiente e del Territo rio e di Scienze della Terra, Università degli Studi di Milano-Bicocca, Milano, Italy

\begin{abstract}
Pacaya is an active stratovolcano located $30 \mathrm{~km}$ south of Guatemala City, Guatemala. A large $\left(0.65 \mathrm{~km}^{3}\right)$ sector collapse of the volcano occurred 0.6$1.6 \mathrm{ka}$ B.P., producing a debris avalanche that traveled $25 \mathrm{~km} \mathrm{SW}$ of the edifice. The current cone has since been rebuilt within the scarp of this ancestral collapse. Two recent collapses in 1962 and 2010 suggest lateral instability of this volcano. Additionally, layers of pyroclastic material erupted from the nearby Amatitlán caldera cover the region and are likely beneath the edifice. Considering these destabilizing factors, one of the biggest concerns at Pacaya is related to another large lateral collapse of the active cone. To assess Pacaya's stability, standard engineering methodologies for studying non-volcanic slopes are used to examine the SW flank of the edifice. A geomechanical model was developed based on the physical-mechanical material properties of Pacaya's intact rocks and rock mass characteristics found through field observations and laboratory tests. Slope stability was analyzed in several scenarios with the Limit Equilibrium Method (LEM) and Finite Element Method (FEM), including static conditions (under gravity forces only), and considering the application of magma pressure and seismic force as triggering mechanisms for slope failure. The study shows
\end{abstract}

*The material in this chapter has been submitted to the journal Bulletin of Volcanology 
that the edifice remains stable under gravity alone, however a large-scale collapse could be triggered by reasonable ranges of magma pressure $(\geq 7.7 \mathrm{MPa}$ if constant along a dyke) or peak ground acceleration (PGA) $\left(\geq 460 \mathrm{~cm} / \mathrm{s}^{2}\right)$. Results also suggest that pyroclastics beneath the edifice could have been a feature which controlled the ancestral collapse. Structural analysis shows that a transtensional stress regime is causing a NW-SE orientation of aligned features at the surface, and may be a controlling mechanism for the direction of a future collapse. FEM results are concordant with those from LEM and reveal that maximum shear strain patterns within the edifice may account for long lava flows erupted from lower vent elevations.

Keywords Volcanic slope stability, Limit Equilibrium Method, Finite Element Method, Pacaya

\subsection{Introduction}

Volcanic landslides, which have caused over 20,000 fatalities in the past 400 years (Siebert et al. 1987), are extremely hazardous geologic processes due to their size and velocity. The largest events (sector collapses) can travel at speeds of 50 to $150 \mathrm{~m} / \mathrm{s}$ (Ui et al. 1986; Siebert et al. 1995), producing several cubic kilometers of debris up to tens of kilometers away from the volcano. Geological and structural studies revealed that some volcanoes are prone to repeated lateral collapse events (see review in Tibaldi and Lagmay 2006). These events can be a serious threat to the conterminous areas, especially for those volcanoes that suffered multiple collapse events in their history.

The past occurrence of catastrophic collapse, continual eruptive activity, and inherent geologic features of Pacaya volcano (Guatemala) demands an evaluation of potential future collapse hazards. Furthermore, Pacaya is surrounded by several communities totaling approximately 9000 people that live less than $5 \mathrm{~km}$ from the active cone and have been evacuated 11 times in the past 24 years (Matías Gómez 2009). A collapse of the active cone would greatly 
expand the hazard zones, therefore it is critical to understand the factors affecting slope stability. Recently, standard engineering methodologies for studying non-volcanic slopes using geomechanical models have been borrowed for studying volcanic slopes (see del Potro and Hürlimann 2008 and references therein). However, numerical data on the relevant mechanical properties remain a major source of uncertainty due to the lack of direct measurements (Thomas et al. 2004; del Potro and Hürlimann 2008). This paper will give an example of how it is possible to merge together different techniques in the field and laboratory for a better rock mass characterization of volcanic slopes and slope stability evaluation. We report new field geological, structural, rock mechanical and geotechnical data on Pacaya. This data is integrated with laboratory tests to better define the physical-mechanical rock mass properties. Finally, this data is used in numerical models for the quantitative evaluation of lateral instability of large sector collapses and shallow landslides.

\subsection{Background}

Pacaya is an active stratovolcano in the Central American Volcanic Arc, associated with the subduction of the Cocos tectonic plate beneath the Caribbean tectonic plate (Fig. 3-1a). Regionally, the study area is located south of the active Motagua and Polochíc left-lateral fault zones on the Caribbean tectonic plate which is subjected to about $8 \mathrm{~mm} / \mathrm{yr}$ of crustal extension (Burkhart and Self 1985; Guzman-Speziale 2001; Lyon-Caen 2006; Franco et al. 2012). This has formed a series of $\mathrm{N}$-striking grabens, including the Guatemala City Graben (GCG), which presently absorbs most of the E-W extensional deformation. Additionally, this area is split by the WNW-striking right-lateral strike-slip Jalpatagua fault zone (JFZ), which moves at a relative rate of 10-14 mm/yr (Carr 1976; Lyon-Caen 2006; Franco et al. 2012). Pacaya is situated at or near the intersection of the GCG and the JFZ on the south rim of the Amatitlan caldera (Fig. 3-1b). The exact location and width of the JFZ is not well defined, 

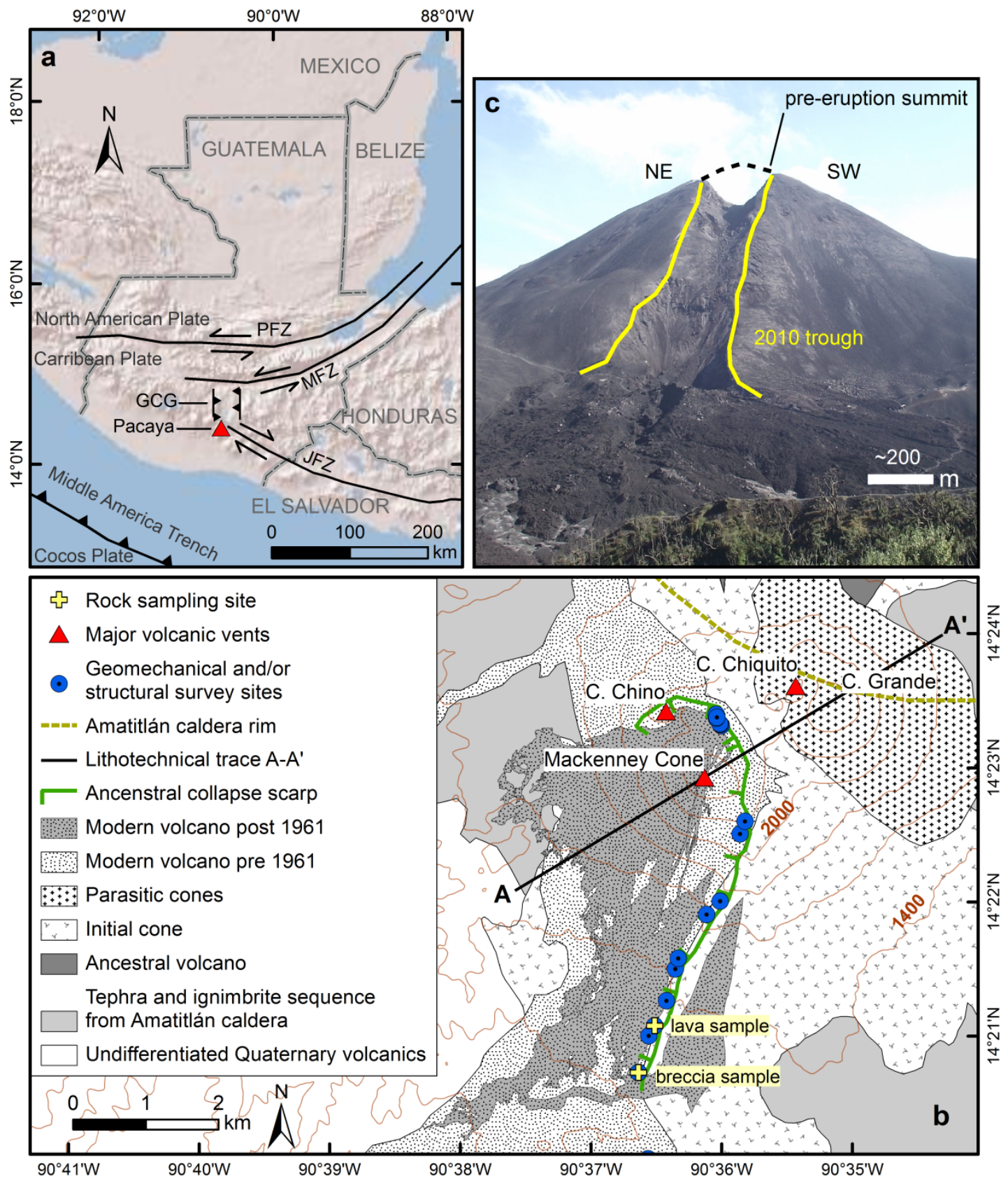

Figure 3-1 Location of Pacaya volcano and main geologic and structural features. a) Pacaya is located just south of the intersection of the right lateral Jalpatagua fault zone (JFZ) and the Guatemala City Graben (GCG) extensional zone. To the north are the Polochíc (PFZ) and the Motagua fault zone (MFZ), which separate the Caribbean from the North American tectonic plates (modified from (Burkhart and Self 1985) and (Lyon-Caen 2006) b) General geology (modified from IGN / Eggers 1969 and Bardintzeff and Deniel 1992) c) Collapse trough on the NW side of the Mackenney cone from 2010 eruptions. 
but the available geologic maps for the area (IGN and Eggers 1969; Eggers 1972; Carr 1976; IGN and Bonis 1993) show a system of faults that run parallel to the main (and most obvious) topographic expression of the fault trace, and which if projected would intersect Pacaya to the NW.

Pacaya is a volcanic complex of several cones with a maximum elevation of $2500 \mathrm{~m}$ above sea level (asl), distinguished into four major phases proposed originally by Eg'gers (1972) and modified by Bardintzeff and Deniel (1992): (1) an ancestral andesitic volcano which is heavily eroded and capped with pyroclastics from the Amatitlán caldera; (2) the initial cone comprised of large lava flows, dated to about 0.5 Ma; (3) emplacement of the Cerro Grande and Cerro Chiquito scoria cones on the NE flank about $0.16 \mathrm{Ma}$; and (4) the modern post-collapse cone. Sometime between 0.6-1.6 ka B.P., the SW sector failed in a major edifice collapse of the initial cone, forming an avalanche that traveled 25 $\mathrm{km} \mathrm{SW}$ and contained about $0.65 \mathrm{~km}^{3}$ of debris (Kitamura and Matías Gómez 1995; Vallance et al. 1995). This event left a large arcuate scarp, within which the modern cone rebuilt (Fig. 3-1b) through historical times up to the present. After intermittent activity in the $19^{\text {th }}$ century, Pacaya entered a period of repose (Feldman 1993). Activity renewed in 1961 and has since loaded 100 to $150 \mathrm{~m}$ of lava flow and tephra material primarily on the SW flank of the cone. This formed the active Mackenney cone (Fig. 3-1b), with the most recent activity occurring in 2010. The post-collapse cone is composed of predominately interbedded lava, breccia, and pyroclastics (mainly air-fall tephra and spatter). There are no significant petrographic differences between the prehistoric, historic, and modern lavas which are porphyritic basalt with olivine and plagioclase phenocrysts (up to 45\%) and microphenocrysts, and minor clinopyroxene and magnetite microphenocrysts (Bardinezteff and Deniel 1992; Matías Gómezet al. 2012).

Several factors at Pacaya can be considered potentially hazardous to the edifice's stability. One is the recent coincident summit Strombolian eruptions, collapse features, and flank lava eruptions that suggest the possibility of magma 


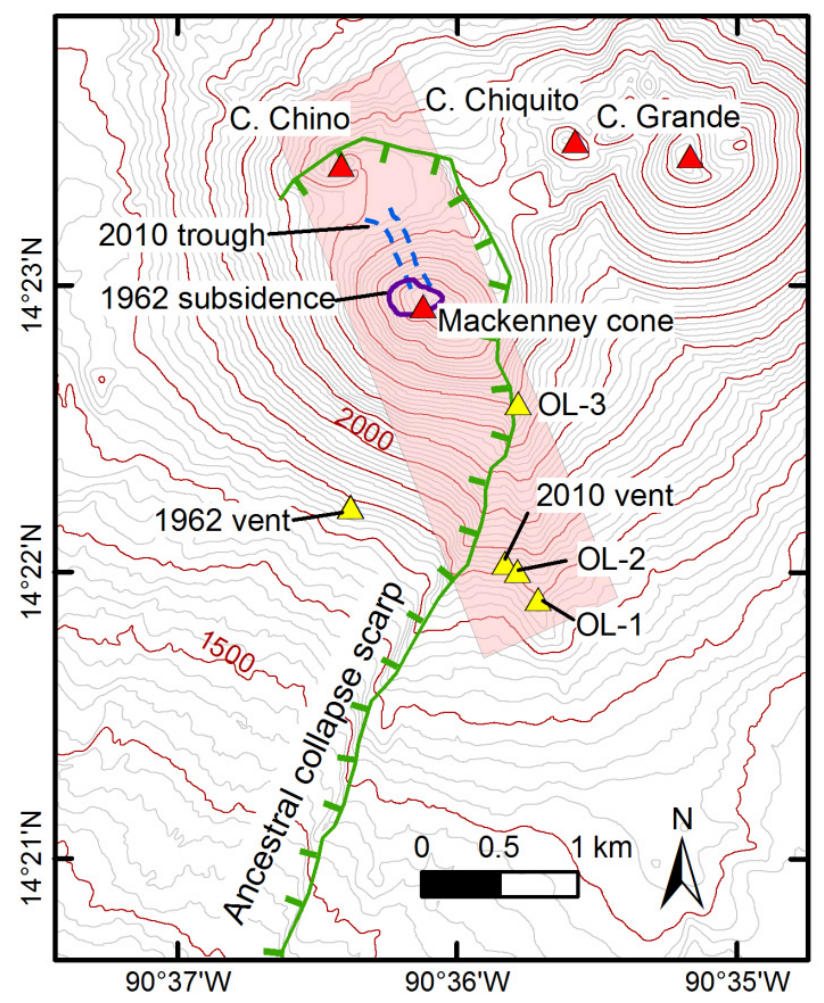

Figure 3-2 Orientation of major vents and recent collapses suggests a preferential NNW orientation of magma ascent (shown in pink box), facilitated by the regional stress regime. The location of vents of older flows are marked by OL-1, OL-2, and OL-3.

reservoirs high in the cone, an idea that has been hypothesized previously (Eggers 1983; Vallance et al. 1995; Matías Gómez 2009). A shallow magma chamber could be an influencing factor in recent collapses, the first of which occurred in 1962 when an oval-shaped area subsided near the summit, coinciding with a long lava flow from a vent at the base of the cone (see '1962 vent' Fig. 3-2). This depression has since been filled with material from later eruptions. During eruptions in May 2010, a second collapse occurred when a linear trough developed on the NW side of the cone during eruptive activity (Fig. 3-1c and 3-2). This trough, which extends $600 \mathrm{~m}$ from the summit, appeared only a few days before a long lava flow was produced from a vent at the base of the cone outside of the ancestral collapse scarp (see '2010 vent', Fig. 3-2). Another factor to consider in stability analysis of Pacaya is a thick layer of tephra and 
ignimbrite sequence that was deposited over the region prior to the formation of the initial cone (Fig. 3-1b) (Eggers 1972; Wunderman and Rose 1984; Vallance et al. 1995). The combination of historic shallow collapses, past occurrence of catastrophic collapse, layer of pyroclastics beneath the edifice, and recent asymmetrical accumulation of new material on a preexisting cone all increase the potential for slope failure.

\subsection{Methodology and results}

\subsubsection{Structural analysis}

Structural surveys comprise analyses of brittle discontinuities and collection of data on the morphometry of volcanic features. The former were performed in the field to determine the local stress regime and most likely location of slope failure. Along the scarp, fractures and joints were measured at the geomechanical survey sites (Fig. 3-3). The results on the brittle discontinuities indicate that both $\mathrm{N}$-striking planes parallel to the regional grabens and NW-striking planes parallel to the Jalpatagua shear zone are reflected in the fracture and joint patterns measured along the scarp. Mapped fault orientations within $50 \mathrm{~km}$ from Pacaya (compiled from Carr 1976; IGN and Bonis 1993 ) also reflect the orientation of the main tectonic features so far described.

Morphometric analyses of volcanic features have been done by field work and study of aerial photos in order to individuate the weakness zones possibly used as magma paths. Following Nakamura (1977), the orientation of fissures and the distribution of dykes and parasitic vents can be related to the state of the regional stress on which a volcano is emplaced. A system of dykes radiating from a central conduit will tend to "bend" and align parallel with the direction of the principal horizontal (regional) compressive stress (or equivalently, perpendicular to the principal tensional stress). In the case of Pacaya, the orientation of the trough formed during the May 2012 eruption is in a NNW direction (Fig. 3-3). This orientation also coincides with the opening of the new vent that formed on the SE 


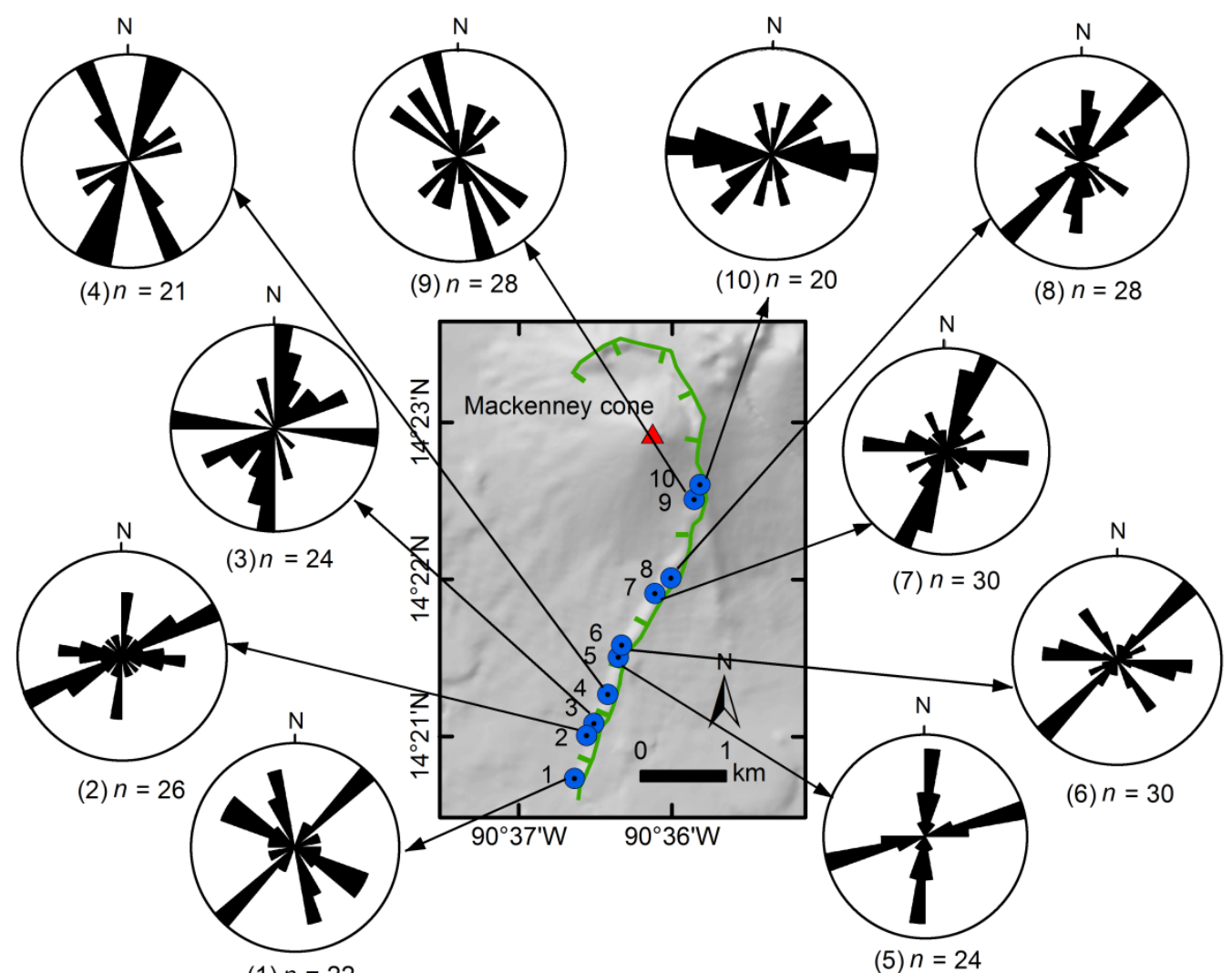

(1) $n=22$

Figure 3-3 Rose diagrams show the geometry of the joints and fractures at survey sites along Pacaya's scarp, with $n$ being the number of joints and fractures measured.

flank of the volcano, and with older important vents e.g. Cerro Chino, and the vents of older flows partially mapped by Eggers (1972) and re-mapped in this study based on aerial orthophotos (labeled as OL-1, OL-2, and OL-3 in Fig.3-2).

Other morphological cues can suggest the preferential orientation of vents and therefore of the dykes that radiate from a central conduit, such as the growth of the volcanic edifice being elongated in the direction of preferential vent formation (Nakamura 1977). This also applies to Pacaya, as can be easily seen from the shape of the elevation contours (Fig. 3-2), and it coincides again with the NNW orientation noted before. Most significantly, the NNW orientation is perpendicular to the direction of the last debris avalanche collapse. 


\subsubsection{Rock mass properties}

\subsubsection{Geotechnical model}

A geological cross-section of the volcano was drawn (Fig. 3-4a) with the geometry of the SW flank being obtained from Digital Elevation Models (DEMs) from 2001 (JICA et al. 2003). Then, a geotechnical model of the volcano was constructed to be used in LEM and FEM modeling (Fig. 3-4b). For numerical modeling purposes, geological units can be simplified and categorized into lithotechnical units according to their mechanical characteristics based on field observations and geological maps. Along the scarp, an alternating pattern of lava and breccia rocks can be projected and used as a good indication of the interior stratigraphy of the volcano. Pacaya has been characterized by other authors as having more or less the same geochemical and petrologic properties throughout its growth (Eggers 1972; Walker 1989; Bardinezteff and Deniel 1992; Vallance et al. 1995). Therefore, we group the rock mass at Pacaya into an alternating lava $(40-70 \%)$ and breccia lithotechnical unit, referred to as lava-breccia (LB) and representing the most prevalent percentage of lava to breccia in the studied outcrops. The rock mass properties for this unit are uniform, representing an intermediate value of lava and breccia rocks found through geomechanical surveys and tests performed along the collapse scarp (location Fig. 3-1b). While the material properties undoubtedly vary throughout this unit due to rock and structural heterogeneity, the small volume, random distribution, and lack of continuity of individual units requires strong assumptions. Therefore, a simplification of this rock mass is necessary and fits the purpose of this conceptual modeling.

An additional complexity to the model was added in considering the thick regional layer of dacite-rhyolitic tephras and ignimbrites. The local stratigraphy below Pacaya is poorly constrained, but from the regional stratigraphy (e.g. Wunderman and Rose 1984) we can assume that this stratigraphy is dominated by ignimbrites, air-fall tephra deposits and volcaniclastic deposits reworked by 


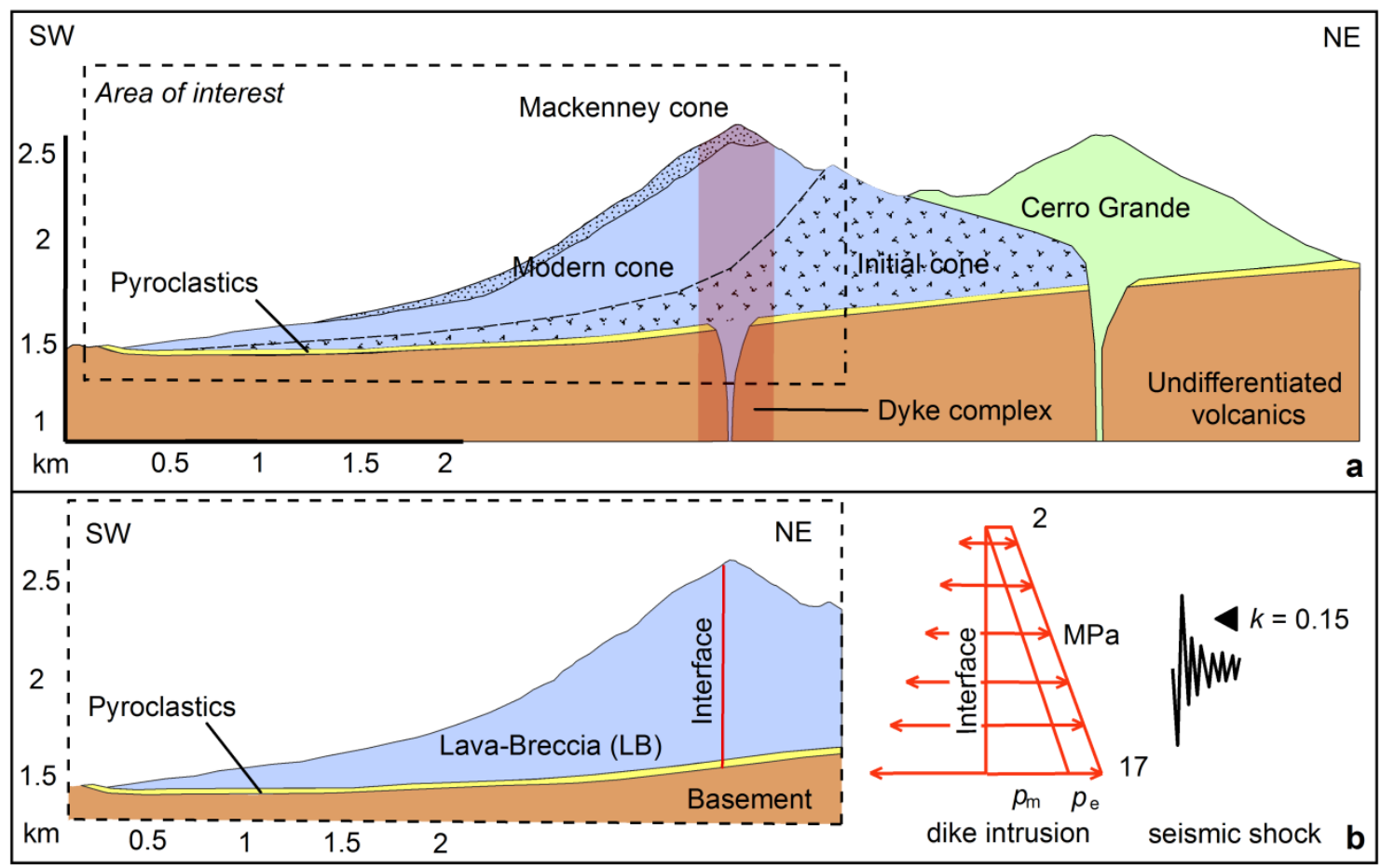

Figure 3-4 a) Geological cross section of Pacaya volcano with major geologicstructural features (trace $A-A^{\prime}$ in Figure1b). b) Cross section showing lithotechnical units (lava-breccia, pyroclastics and basement) and location of the physical interface representing the dyke. In the inset, representation of external forces seismicity and magma pressure. Magma pressure components include the magmastatic pressure $\left(p_{m}\right)$ due to magma weight with a triangular distribution, and magma overpressure $\left(p_{e}\right)$ due to excess-pressure added as a constant along the interface height.

secondary processes. For the purpose of this work we assume the presence of a hypothetical layer of tephras and intercalated paleosols with an aggregated thickness of $30 \mathrm{~m}$, similar to the exposed sequences that can be found to the north of the Amatitlán Caldera (Wunderman and Rose 1984). Because this pyroclastic material was not tested in the field beyond visual estimates, data from the literature for similar products was used (Thomas et al. 2004; Apuani et al. 2005a, b; del Potro and Hürlimann 2008). Both of these units, which are modeled according to an elasto-plastic constitutive law, sit on top of a "basement" (representing undifferentiated volcanics) which is assumed to be a rigid body. In FEM analysis, boundary conditions at the sides of the model are fixed in both the ' $x$ ' and ' $y$ ' direction and the lower boundaries were extended to avoid boundary 
effects on the edifice. Data for the local water table is not a vailable, therefore all model conditions were considered dry.

Table 3-1 summarizes the ranges and values used as input data (in brackets) for numerical modeling. These represent the predominate values found through field observations and laboratory tests as described by Schaefer (2012), and summarized in Table 3-2. The physical-mechanical properties (Table 3-1) include both the rock mass properties necessary for the Hoek-Brown failure criterion (Hoek 1994) and the calculated Mohr-Coulomb rock mass equivalent parameters necessary for LEM and FEM analysis.

\section{Table 3-1}

Physical and mechanical properties of the lava-breccia (LB) and pyroclastics lithotechnical units

\begin{tabular}{|c|c|c|}
\hline & \multicolumn{2}{|c|}{ Lithotechnical Units } \\
\hline & Lava-Breccia & Pyroclastics \\
\hline & $40-70 \%$ lava & $\begin{array}{l}\text { pyroclastic } \\
\text { deposits }\end{array}$ \\
\hline \multicolumn{3}{|l|}{ Hoek-Brown failure criterion parameters } \\
\hline Intact rock- $\sigma_{\mathrm{ci}}(\mathrm{MPa})$ & $52^{\mathrm{Lb}, \mathrm{S}}$ & $10-20(20)^{*}$ \\
\hline Geological Strength Index- GSI & $45-60(50)^{\mathrm{S}}$ & $8-20(15)^{S}$ \\
\hline $\mathbf{m}_{\mathbf{i}}$ & $22 \pm 5(22)^{T r}$ & $13 \pm 5(13)^{\top r}$ \\
\hline Disturbance factor- $D$ & $0^{S}$ & $0^{S}$ \\
\hline Unit weight- $Y\left(k N / m^{3}\right)$ & $25.65^{\mathrm{Lb}}$ & $8-20(15)^{*}$ \\
\hline \multicolumn{3}{|c|}{$\begin{array}{l}S \text { in situ direct tests and evaluations, } \operatorname{Tr} \text { theoretical data, } L b \text { laboratory results *values from th } \\
\text { literature. Values chosen for input data in brackets when ranges are given. }\end{array}$} \\
\hline \multicolumn{3}{|c|}{ Mohr-Coulomb equivalent parameters in the range of $\sigma_{3 \max }^{\prime}=5-15 \mathrm{MPa}$. } \\
\hline mb & 3.689 & 0.625 \\
\hline $\mathbf{s}$ & 0.004 & 0.0001 \\
\hline a & 0.506 & 0.561 \\
\hline Apparent cohesion- c (MPa) & $1.7-3.6$ & 0.53-1.09 \\
\hline Friction angle $-\varphi\left({ }^{\circ}\right)$ & $45.3-36.1$ & 21.9-15.6 \\
\hline Tensile strength- $\sigma_{t m}^{\prime}(\mathrm{MPa})$ & -0.054 & -0.003 \\
\hline Uniaxial compressive strength- $\sigma_{m}(\mathrm{MPa})$ & 3.132 & 0.1 \\
\hline Global strength- $\sigma^{\prime}{ }_{\mathrm{cm}}(\mathrm{MPa})$ & 13.273 & 1.552 \\
\hline Young's Modulus- $E_{\mathrm{m}}(\mathrm{MPa})$ & 3686 & 437 \\
\hline
\end{tabular}


Table 3-2

Uniaxial compressive strength $\left(\sigma_{\mathrm{ci}}\right)$ from Schmidt hammer and uniaxial compressive tests, and unit weight $(\gamma)$ of volcanic samples. Values are given as the mean \pm the standard deviation, with $n$ being the number of specimens tested.

\begin{tabular}{ccccccc}
\hline & \multicolumn{2}{c}{$\begin{array}{c}\text { Schmidt } \\
\text { hammer tests }\end{array}$} & \multicolumn{2}{c}{$\begin{array}{c}\text { Laboratory } \\
\text { uniaxial tests }\end{array}$} & \multicolumn{2}{l}{ Unit weight } \\
\hline Sample & $n$ & $\sigma_{\mathrm{ci}}(\mathrm{MPa})$ & $n$ & $\sigma_{\mathrm{ci}}(\mathrm{MPa})$ & $n$ & $\gamma\left(\mathrm{kN} / \mathrm{m}^{3}\right)$ \\
\hline Lava & 18 & $88.03 \pm 29.92$ & 12 & $47.62 \pm 16.01$ & 17 & $26.82 \pm 0.11$ \\
Breccia & 10 & $47.6 \pm 11.97$ & 17 & $33.08 \pm 11.26$ & 17 & $22.92 \pm 0.91$ \\
\hline
\end{tabular}

\subsubsection{Slope stability analysis}

\subsubsection{Methodology}

Volcano slope stability was analyzed using LEM in Rocscience Slide 6.0 code. The outcome for the deterministic analysis is the Factor of Safety (FS), which is defined as

$$
F S=\frac{\text { Shear strength of material (soil or rock) }}{\text { Shear strength required for equilibrium }}
$$

and describes the stability of the slope. Because of the presence of weak rocks and complex interior magmatic plumbing systems in volcanic environments, the slope can be assessed as stable ( $F S>1.5)$, moderately unstable $(1.3<F S<1.5)$, inherently unstable $(1<F S<1.3)$ or at failure $(F S<1)$ (Hoek 2007). In this study, the stability of the volcanic slope is analyzed as a two-dimensional (2D) plane strain problem. Previous studies have shown that this assumption provides a lower estimate of stability/FS compared to the three-dimensional (3D) analysis (Michalowski 2010). However, future studies would benefit to consider the 3D effects to better constrain the out of plane extent and volume of potential slope instability.

Slip surfaces in LEM were calculated using the Janbu Simplified method. This method tends to be more conservative than others (Hungr et al. 1989), which is 
justifiable for hazard assessments. A slip surface was not pre-defined, but found using an auto-refined, non-circular search method. This method uses an iterative algorithm to find the "global minimum" slip surface, or surface with the lowest FS, and is suitable for considering irregular slip surfaces.

To follow stress and strain variations within the model when applying different disturbance factors, a 2-D FEM analysis was computed using the Phase2 8.0 code (Rocscience 2011). This 2D elasto-plastic numerical model uses the Shear Strength Reduction (SSR) method, which systematically reduces the strength parameters of a slope by a Shear Reduction Factor (SRF) and then computes the finite element stress analysis. This process is repeated for different SRF values until the model becomes unstable, or the results do not converge. This determines the critical SRF of the slope, a value equivalent to the FS (Rocscience 2011). Conclusions can be made by analyzing the "plasticization" of the model, which refers to a process of failure and fracturing in accordance with engineering mechanics. In particular, "plasticity indicators" show the zones in which the stresses satisfy the yield criterion. This type of analysis allows for a visualization of the development of failure mechanisms and eliminates the need for assumptions on the type, shape, and location of failure surfaces.

In both LEM and FEM analyses, models were evaluated in the following conditions:

Model A: under gravity forces only;

Model B: with magma pressure acting on a dyke;

Model C: applying horizontal acceleration due to a seismic shock.

These were sub-grouped into models with a layer of pyroclastics (A-1, B-1, and $\mathrm{C}-1$ ) and models without (A-2, B-2, and C-2) as outlined in Table 3-3. 
Table 3-3

Deterministic analysis trial conditions and outcomes

\begin{tabular}{lcccccc|cc}
\hline \multicolumn{1}{c}{ Models } & $\begin{array}{c}\text { Pyroclastic } \\
\text { unit? }\end{array}$ & $\begin{array}{c}\text { Unit } \\
\text { Weight }\end{array}$ & $\begin{array}{c}\text { UCS } \\
(\mathrm{MPa})\end{array}$ & Static & $\begin{array}{c}\text { Magma pressure- } p \\
(\mathrm{MPa})\end{array}$ & $\begin{array}{c}\text { Seismic } \\
\text { coefficient }-k\end{array}$ & FS & SSR \\
\hline $\mathrm{A}-1$ & yes & 25.65 & 52 & $\mathrm{x}$ & & & 1.81 & 1.98 \\
$\mathrm{~A}-2$ & no & 25.65 & 52 & $\mathrm{x}$ & & & 2.55 & 2.79 \\
$\mathrm{~B}-1$ & yes & 25.65 & 52 & & $2-17$ (top-bottom) & & 1.08 & 1.00 \\
B-2 & no & 25.65 & 52 & & $2-17$ (top-bottom) & & 1.86 & 1.82 \\
C-1 & yes & 25.65 & 52 & & & 0.15 & 1.20 & 1.26 \\
C-2 & no & 25.65 & 52 & & & 0.15 & 1.94 & 2.13 \\
\hline
\end{tabular}

For each of these conditions, material properties were kept constant (mean values Table 3-4). The same models and model properties from LEM analyses were used in FEM analysis for direct comparison of the results. For several parameters, LEM results were assessed using sensitivity and probabilistic analyses (Monte Carlo sampling technique) to take into account uncertainty in these values. The inputs for these analyses were assumed with a statistical distribution defined by the mean value, standard deviation, and absolute minimum and maximum values (Table 3-4).

\section{Table 3-4}

Sensitivity and probabilistic analysis inputs were assumed with the statistical distribution defined by mean value, standard deviation, and absolute minimum and maximum values

\begin{tabular}{lccccc}
\hline \multicolumn{1}{c}{ Parameter } & Unit & Mean & $\begin{array}{c}\text { Standard } \\
\text { deviation }\end{array}$ & $\begin{array}{c}\text { Absolute } \\
\text { minimum }\end{array}$ & $\begin{array}{c}\text { Absolute } \\
\text { maximum }\end{array}$ \\
\hline $\begin{array}{l}\text { Unit weight }(\mathrm{y}) \text { : Lava-Breccia } \\
\text { Uniaxial compressive strength }\end{array}$ & $\mathrm{kN} / \mathrm{m}^{3}$ & 25.65 & 2 & 10 & 30 \\
$\left(\sigma_{\mathrm{ci}}\right)$ : Lava-Breccia & $\mathrm{MPa}$ & 52 & 23 & 1 & 100 \\
Magma pressure $(\mathrm{p})$ & $\mathrm{MPa}$ & 13.28 & - & 0 & 30 \\
Horizontal seismic coefficient & - & 0.15 & - & 0 & 0.4 \\
\hline
\end{tabular}


Magma pressure $(p)$ acting on a dyke includes the magmastatic component $\left(p_{m}\right)$ and an excess-pressure (or overpressure) component $\left(p_{e}\right)$ (Voight and Elsworth 1997):

$$
p=p_{m}+p_{e}
$$

Magmastatic pressure is a product of mean magma unit weight $\left(\mathrm{y}_{\mathrm{m}}\right)$ and height of the dyke ( $z$ ), and its value increases with depth being maximum at the bottom of the edifice grading to minimum to null at the summit due to stages of decompression. A mean magma unit weight of $22.56 \mathrm{kN} / \mathrm{m}^{3}$ was derived from the mean magma body density based on gravity studies at Pacaya by (Eggers 1983). Assuming the dyke is $1000 \mathrm{~m}$ high (base of the volcano to the summit), a maximum of $p_{m}=22.56 \mathrm{MPa}$ can be calculated based on the following relation (Iverson 1995):

$$
p_{m}=\gamma_{m} \cdot z
$$

Following suggestions by other authors (Apuani et al. 2007; Apuani and Corazzato 2009), the maximum magmastatic pressure was reduced by $1 / 3$ to $p_{m}$ = $15 \mathrm{MPa}$ for modeling. This reduction accounts for variable situations that could reduce the pressure, such as magma moving through multiple conduits or changes due to gaseous and solid phases.

Magmatic overpressure values for dykes feeding eruptions are not well constrained, however (Iverson 1995) suggests $0 \leq p_{e} \leq 10 \mathrm{MPa}$ as a reasonable range for excess magmatic pressure. This study has adopted a low excess pressure of $2 \mathrm{MPa}$ (also according to Rubin and Pollard 1987; Hürlimann 2000) that is applied as constant with depth in addition to $p_{m}$. The total magma pressure $(p)$ values used in modeling ranged from $2 \mathrm{MPa}$ for the top load to $17 \mathrm{MPa}$ for the bottom load, applied as a tensional force and extending $1000 \mathrm{~m}$ from the base of the edifice to the main active vent at the summit (Fig. 3-4). This "interface" simulates the presence of a magmatic feeding dyke. 
To model the effects of earthquake loading in LEM and FEM analysis, a pseudostatic load, in terms of a dimensionless coefficient that represents the maximum earthquake acceleration as a fraction of the acceleration due to gravity. In this case, a horizontal seismic coefficient $(k)$ was used which represents a seismic force directed out of the slope, or in the direction of failure. A recent seismic hazard analysis of Central America (Benito et al. 2012) gives a peak ground acceleration (PGA) range of $500-610 \mathrm{~cm} / \mathrm{s}^{2}$ with a return period of 500 years for the region where Pacaya is located. The horizontal seismic coefficient can be modeled as half PGA when expressed as a fraction of the gravitational acceleration(Hynes and Franklin 1984), therefore a range of 0.25-0.3 can appropriately describe the largest expected seismic event in the study area for a 500 year return period. To model a more probable earthquake event, or an earthquake with a lower return period, a lower value of 0.15 (PGA of $300 \mathrm{~cm} / \mathrm{s}^{2}$ ) was used for deterministic analysis.

\subsubsection{LEM results}

In static conditions, the slope is always stable $(F S>1.5)$. Sensitivity analysis shows that material properties would have to be reduced to unrealistic values to induce the slope to fail (Fig. 3-5a and 3-5b). In model A-1, the UCS value for the LB unit would have to be reduced to $18.17 \mathrm{MPa}$ (friction angle equivalency of $23.52^{\circ}$ ) for $\mathrm{FS}=1.5$, and $1.94 \mathrm{MPa}$ (friction angle of $11.45^{\circ}$ ) for $\mathrm{FS}=1$, a reduction of $65 \%$ and $96 \%$ respectively from the input values. These values are even higher in model A-2, with UCS reduced to $11.4 \mathrm{MPa}$ for FS=1.5 and $0.64 \mathrm{MPa}$ for $F S=1$. These values suggest that the reduction of material properties should not initiate a deep-seated landslide.

However, magma pressure in a dyke can act as a destabilizing factor: if kept constant along the dyke, the slope reaches an unstable range $(F S<1.5)$ when magma pressure reaches $2.9 \mathrm{MPa}$, and failure ( $F S<1)$ at $7.7 \mathrm{MPa}$ in model $\mathrm{B}-1$ (Fig. 3-5c). In model B-2, these pressures are 8.4 and $15.6 \mathrm{MPa}$, respectively. These values are well under the expected maximum of $17 \mathrm{MPa}$. The inclusion of 

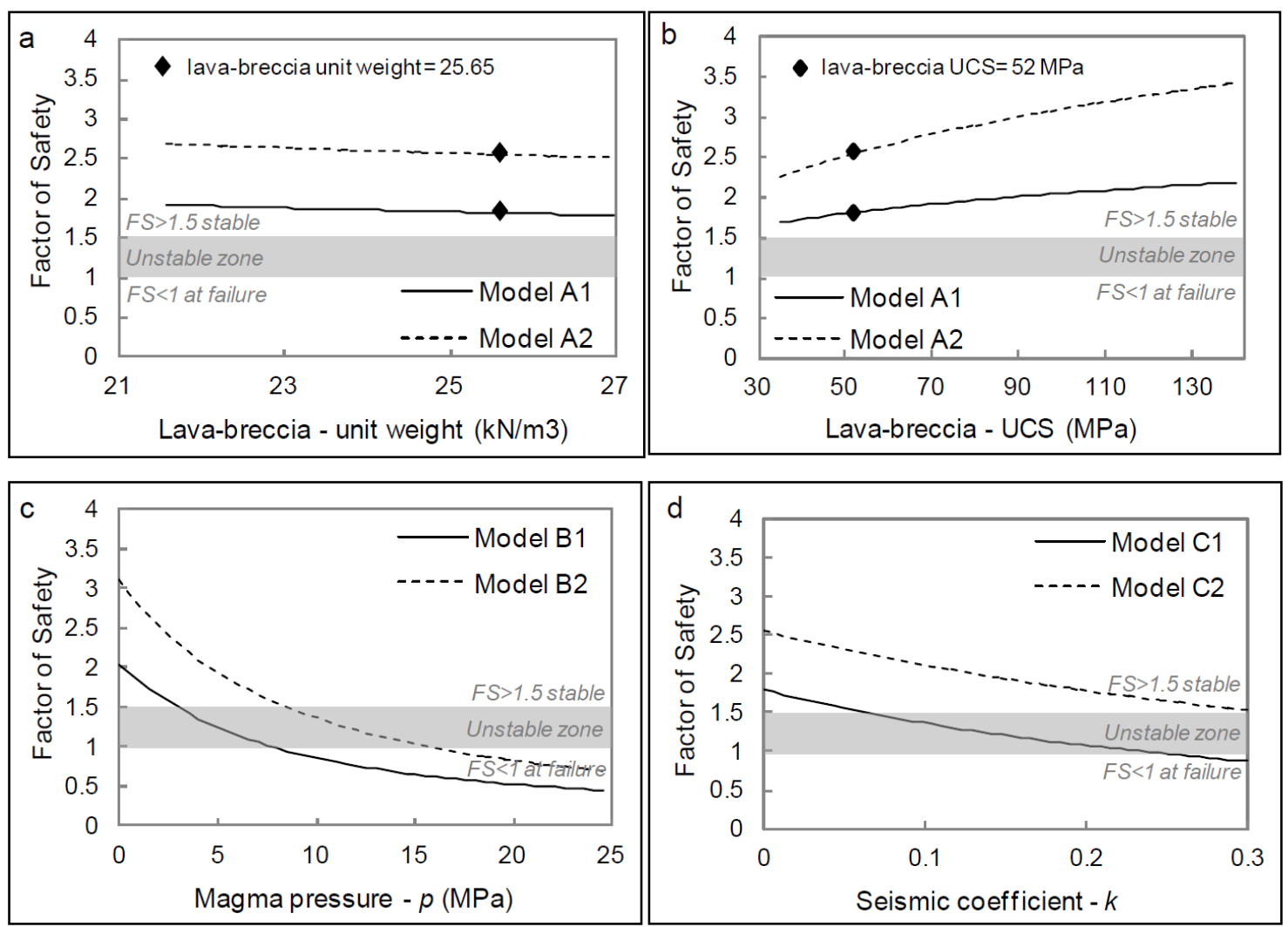

Figure 3-5 Sensitivity analysis of unit weight (5a), UCS (5b), magma pressure (5c), and seismic coefficient (5d) in model conditions A-C. The UCS of the lavabreccia unit would have to be reduced to unrealistic values to induce failure, however magma pressure in a dyke and seismic acceleration can result in instability $(\mathrm{FS}<1.5)$ within expected ranges.

pyroclastics beneath the edifice (model A-1) greatly increases the depth of the slip surface and the amount of material predicted to fail (Fig. 3-6). This change in geometry was also true in models B-1 and C-1. In all cases, the probability of the mass reaching instability is considerably higher in models with pyroclastics as seen in probabilistic analyses (Fig. 3-7), emphasizing the effect that weak units can have on edifice stability.

Seismic acceleration can also cause the slope to reach the unstable zone. For model $\mathrm{C}-1, \mathrm{FS}<1.5$ when the seismic coefficient reaches 0.06 , and FS $<1$ at 0.23 (Fig. 3-5d). Again, these values are well under the expected range of 0.25-0.3 for the maximum seismic coefficient. The seismic loading required to destabilize 


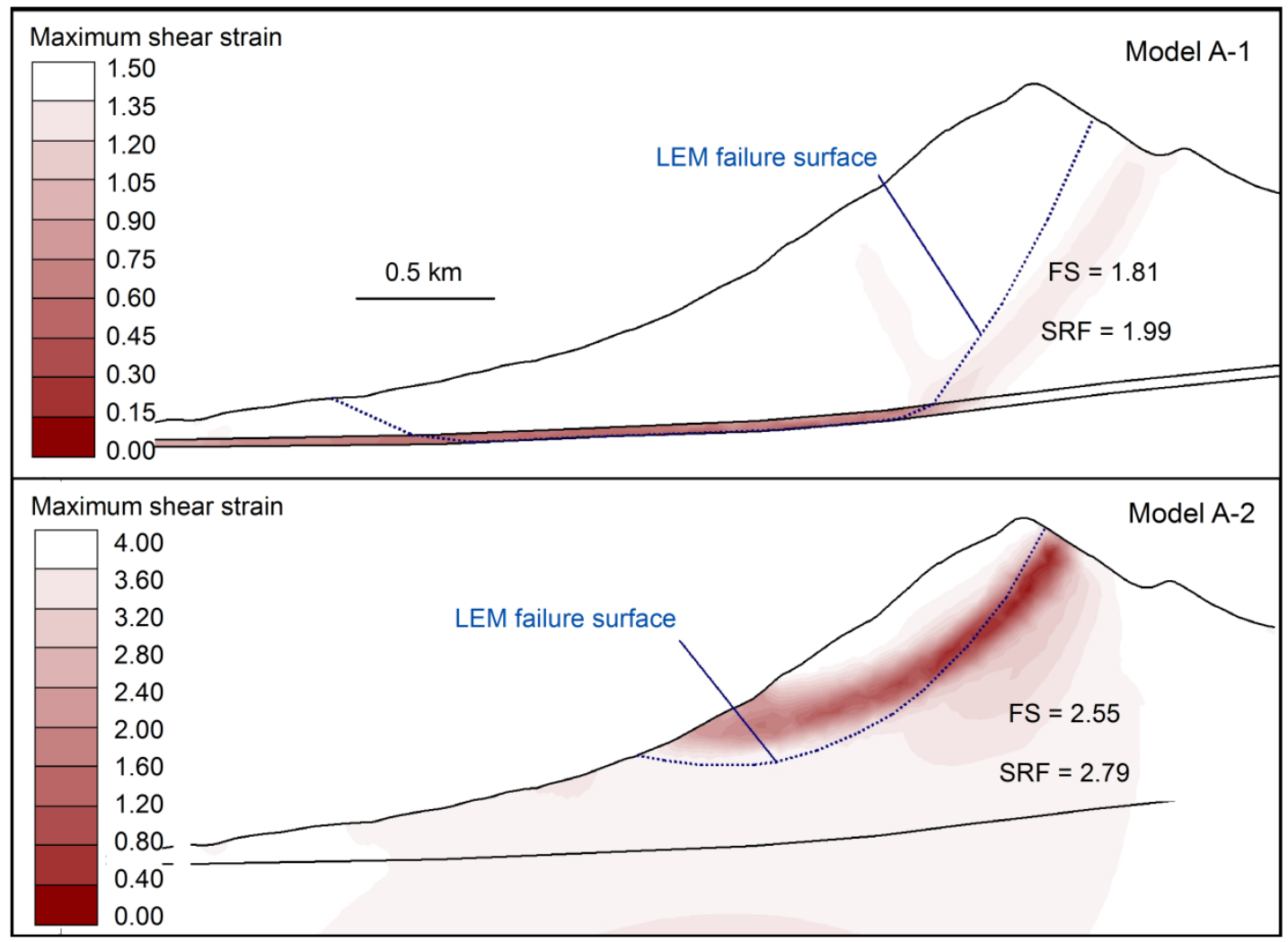

Figure 3-6 LEM critical slip surface superimposed on the contours of FEM maximum shear strain for model A-1 (top) and model A-2 (bottom). This change in geometry was also true in models $B$ and $C$. The unstable mass geometry outlined in the models with pyroclastics resembles the magnitude of the ancestral collapse, suggesting that pyroclastic deposits beneath the edifice could have been a feature that controlled that collapse.

model C-2 without the pyroclastic unit is slightly higher than the expected maximum range, with $\mathrm{FS}=1$ at 0.31 and $\mathrm{FS}=1.5$ at values $>0.4$, therefore an earthquake capable of producing much larger accelerations would be required to destabilize the slope in this situation, corresponding to a much longer return period, probably longer than 1000 years (Benito et al. 2012).

Cumulative probability analysis shows that the probability of the slope reaching instability ( $F S<1.5)$ is $90 \%$ for model B-1 and $30 \%$ for model B-2 (Fig. 3-7), the first being a considerably high probability. In models where seismic force is applied, the mass reaches instability $(\mathrm{FS}<1.5)$ at $78 \%$ for model $\mathrm{C}-1$, for only $4 \%$ 


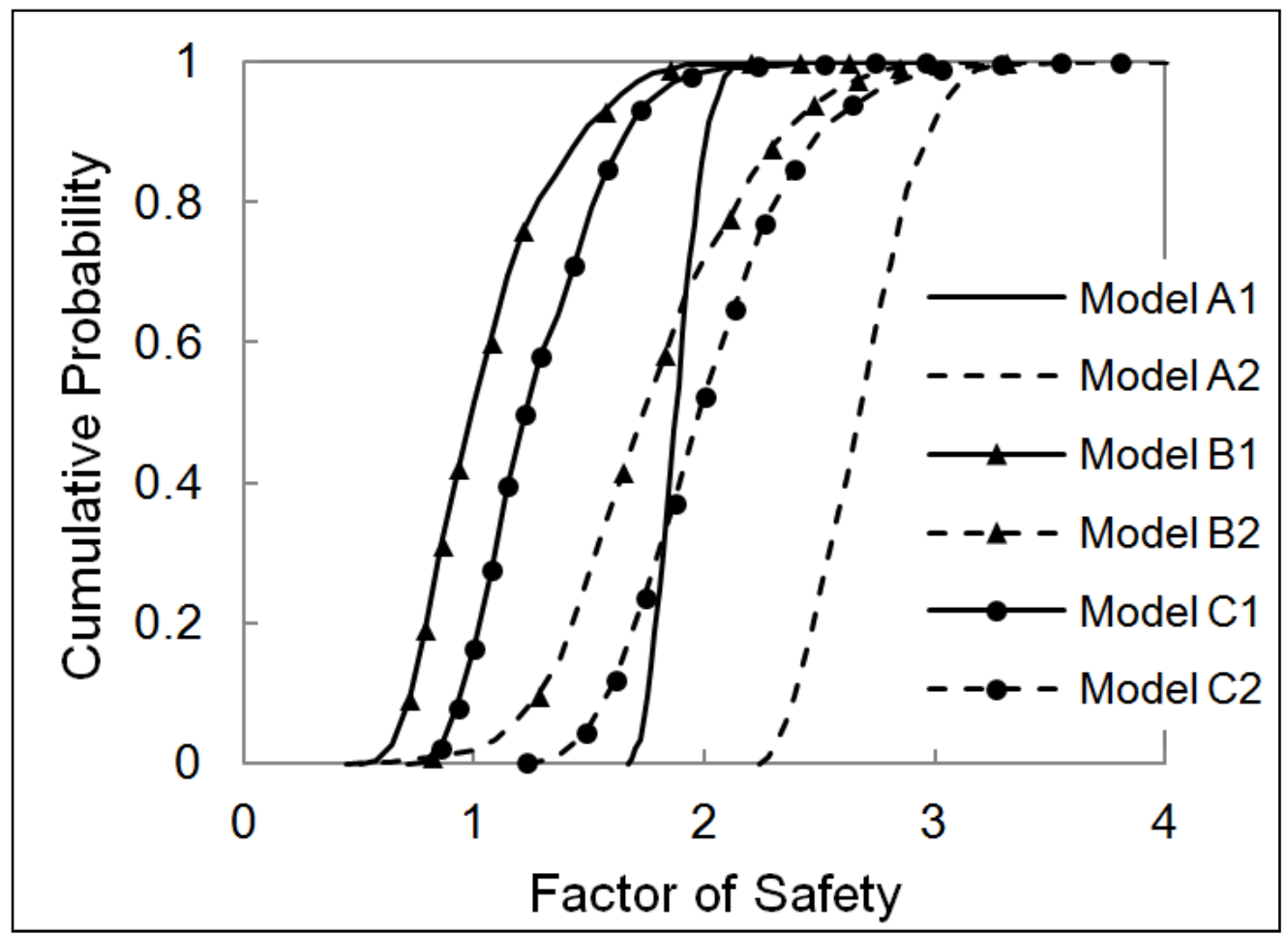

Figure 3-7 Cumulative probability of failure for each model condition. FS = 1 and 1.5 marked by grey dotted lines.

for model C-2. Both sets of these values indicate that unless a weak layer exists beneath the edifice, the probability of these triggers causing a large slope failure alone is relatively low.

\subsubsection{FEM results}

Unless otherwise stated, results discussed are for the critical SRF stage, or when results do not converge for FEM analysis. The location of maximum shear strain within the edifice and displacements of the edifice vary significantly for models with and without the layer of pyroclastics (Fig. 3-8). In models with a layer of pyroclastics, the area of maximum shear strain is concentrated within the pyroclastics and daylights at the surface only when the model reaches its critical state. Displacements within these models tend to be equal from the top to the bottom of the cone. In contrast, models without a layer of pyroclastics tend to develop shear strain within the middle to top of the cone which develops through 
intermediate stages until reaching the surface at the top of the cone and around 1600-1800 m.

When magma pressure is applied, deformation develops as a bulge in the middle of the cone (Fig. 3-9), and continues to develop this bulge through slope failure. The application of seismic acceleration produces areas of maximum shear strain in similar patterns in models $A$ and $B$. However, the models with seismic force have lower SSR values (see Table 3-3) and higher shear strain (Fig. 3-8).

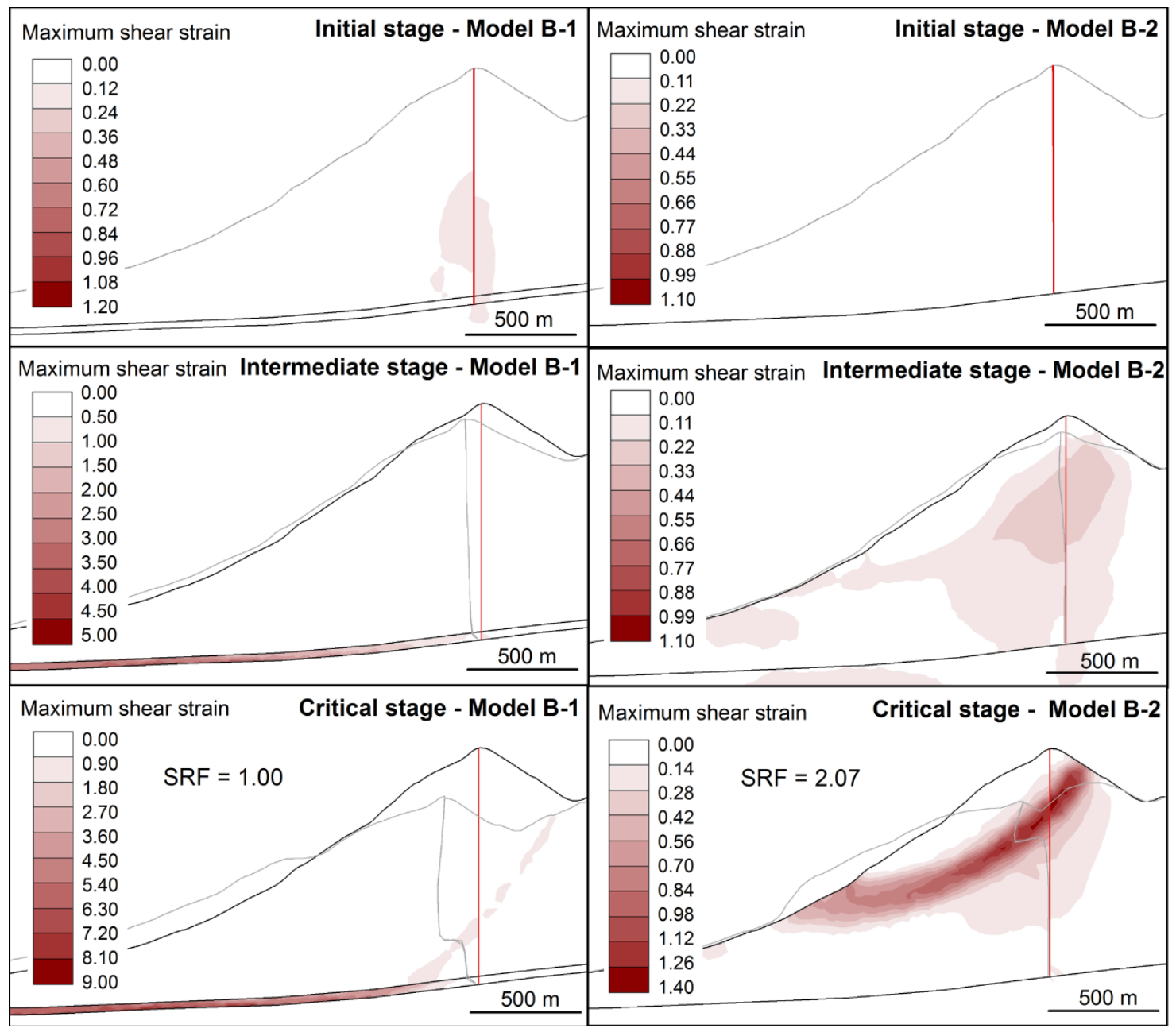

Figure 3-8 FEM shear strain and displacement vectors of magma application (B$1, \mathrm{~B}-2)$ and seismic force (C-1, C-2). Results are for the critical SRF stage. 


\subsection{Discussion}

3.4.1 The lesson from the previous geological history

By considering the previous history of the volcano, it is possible to make predictions of the most plausible orientation of lateral failures, i.e. only to assess the possible preferential direction of failure. The field geological-structural data indicate the presence of brittle discontinuities that strike N-S and NW-SE. Their strike and dip angle indicate they are parallel to regional structures, comprising the N-striking GCG, and the NW-striking right-lateral strike-slip JFZ. The orientation of the GCG is coherent with an E-W-trending $\sigma_{3}$, which is consistent with the orientation of $\sigma_{3}$ along the JFZ. Acting together, these features could indicate an ENE tensional component in a transtensional setting, perhaps resulting from the superposition of the right lateral shearing of the JFZ and the extension happening to the north of Pacaya, at the GCG. These ideas are compatible with research on the regional tectonic deformation and stress state in the area as documented by (Guzman-Speziale 2001; Caceres et al. 2005; LyonCaen 2006; Álvarez-Gómez et al. 2008; Franco et al. 2012).

Our morphometric analysis of the orientation of past and recent volcanic craters and fissures indicates that the currently active and ancestral Cerro Chino vents, the new vents and the 2010 trough feature are all aligned in a NNW-SSE pattern (Fig. 3-2). We can consider these aligned features as the expression of a weakness zone that favored magma upwelling to the surface. This volcanic rift zone is perpendicular to the regional ENE-WSW $\sigma_{3}$, thus we consider that the geometry of the NNW-trending volcanic rift of Pacaya may be controlled by regional tectonics. Moreover, the SW orientation of the ancestral collapse may have been geometrically guided by the orientation of the NNW weakness zone.

If we take into consideration all the aforementioned features, the most likely direction of a future collapse is aligned roughly NE-SW. The presence of the Cerro Chino and Cerro Chiquito cones on the NE flank of the volcano is likely 
acting as a buttress and this, paired with recent loading of lava flow material on the SW flank, suggests that the most likely direction for a possible future collapse will be to the SW.

\subsubsection{Slope stability evaluation}

In studying the stability of the SW flank of the Pacaya volcano using LEM and FEM approaches, various destabilizing processes have been considered. In simulating poor mechanical properties or a drastic reduction in rock properties (i.e. through hydrothermal alteration), sensitivity analyses of material properties show that weak materials are unlikely to induce failure as a single mechanism for a large-scale landslide. This is especially true given the relatively young age of the edifice, making it unlikely that extensive hydrothermal alteration has occurred. Therefore, the slope is highly unlikely to have a catastrophic failure under gravity alone, unless affected by another mechanism. However, the consistent LEM failure surface and FEM shear strain pattern throughout all three models at the critical stage indicates that the material properties and geometry of the slope, and not external triggers, are the driving force behind the failure geometry patterns.

Models show that shear strain can be concentrated at elevations around 1600$1800 \mathrm{~m}$ asl. This is the same elevation that the 2010 vent and other older vents have opened on the slope of Pacaya. Maximum shear strain zones can partially explain this trend, as shear fractures can act as conduits for magma to drain out at lower vents (Fig. 3-9). The differences in the location of shear strain and types of displacements seen between the two model subcategories ( 1 and 2 ) in models A-C have given important insight into collapse behavior. If indeed there is a layer of pyroclastics beneath the edifice, geodetic studies will likely show an overall deformation of the slope as the cone slowly slides along this layer of pyroclastics (Fig. 3-10). If this layer does not exist, or is not the controlling feature of collapse, 

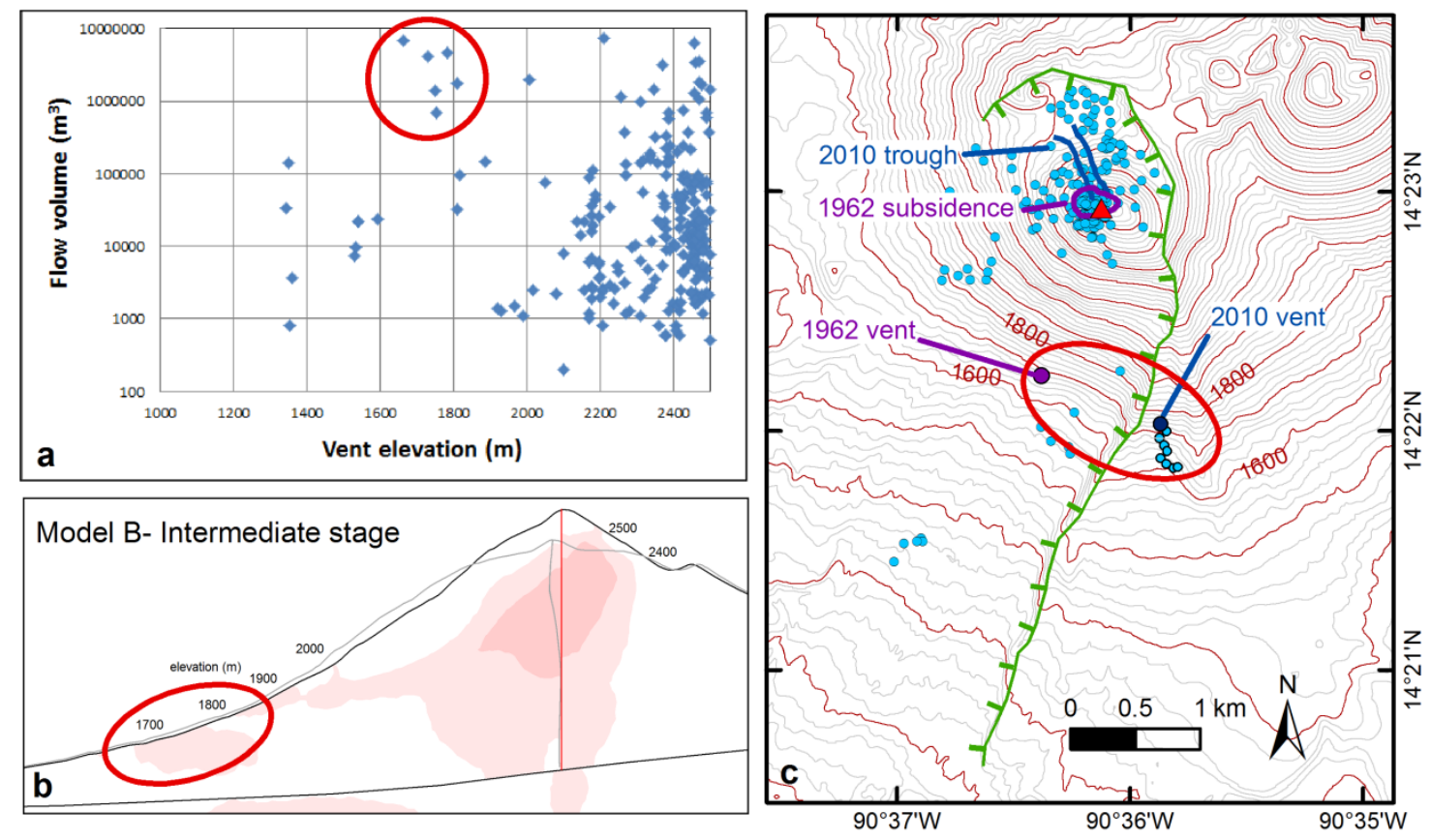

Figure 3-9 Vents that have produced large lava flows $\left(1,000,000 \mathrm{~m}^{3}\right.$ or greater $)$ are clustered at the top of the cone and at an elevations of 1600 to $1800 \mathrm{~m}$ a Plot of flow volume vs. vent elevation b FEM analysis shows maximum shear strain patterns in the same elevation during an intermediate staqe of magma pressure application c Map of 1961-2012 vents mapped (Matías Gómez et al. 2012) and the local transtensional setting (inset).

then instead we will likely see concentrated deformation where the magma pressure is being applied within the edifice. This idea should be explored further.

Both magma pressure and seismic activity can destabilize the slope within reasonable ranges for Pacaya, with magma pressure having the strongest effect among the cases analyzed. Although the slope can fail in what is considered to be the unstable range $(1<\mathrm{FS}<1.5)$, values necessary to reach more definite slope failure $(F S<1)$ suggest that a larger magma intrusion (magma pressure $\geq$ 7.7 MPa if constant along a dyke) or seismic event (PGA $\geq 460 \mathrm{~cm} / \mathrm{s}^{2}$ ) is likely to trigger a catastrophic collapse. The high values of maximum displacement in models $B$ and $C$, ranging from 232-656 $\mathrm{m}$, suggest that these triggers are capable of a push violent enough to displace large amounts of material. For greater accuracy in applying seismic force, horizontal seismic coefficients should 


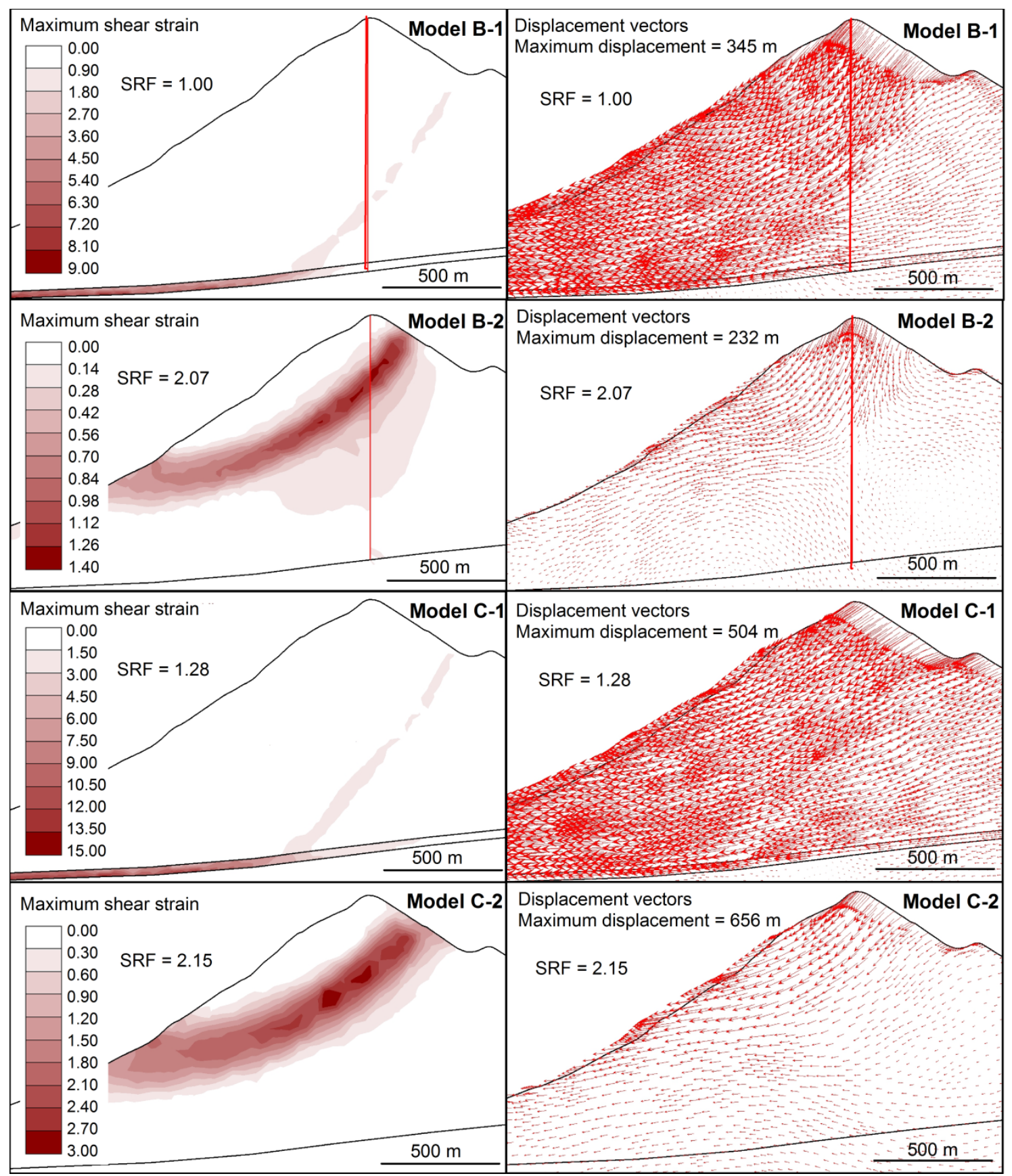

Figure 3-10 Development of maximum shear strain within the edifice and deformation of the slope (in grey) during magmatic application. Models range from the initial stage with no magma pressure (top) to the critical stage when the model is at failure (bottom). 
be verified using a more detailed seismic hazard analysis of the area considering local sources and possible site effects. Additionally, the effects of ground deformation caused by fault rupture and movement from a potential seismic fault underneath the Pacaya edifice (e. g. and extension of either the strike-slip JFZ or extensional GCG normal faults), could also cause the collapse of the volcanic edifice; such possibilities have not been considered in this study.

The unstable mass geometry outlined in the models with pyroclastics resembles the magnitude that is expected of the large ancestral collapse. This suggests that the layer of pyroclastics could have been a feature which controlled the ancestral failure, and could be an important controlling mechanism of a future collapse. Additionally, models with the layer of pyroclastics have a higher probability of reaching instability than those without. Therefore, it is important to better determine the mechanical properties of such hypothesized layers, and to obtain better estimates of their locations and thicknesses beneath the edifice.

The presence of vents aligned across the Pacaya cone, defining a potential NNW-SSE structurally weak zone, indicates that dyke injection can be a plausible geometry for the surface magma plumbing system, similar to what found for example at Stromboli volcano or at Reunion Island (Corazzato et al. 2008; Bonali et al. 2011). Dyke intrusion produces strong deformations and lateral magma push, thus combining these data with our numerical modeling suggests that large magma upwelling events at Pacaya might strongly destabilize the cone in the deeper parts as well as at shallow zones in the future, with special reference to the SW sector of the cone. We thus conclude that the development of landslides is a serious threat to the area.

\subsection{Conclusions}

The analysis of the regional tectonic and structural setting, as well as the local structures at Pacaya, suggest that the local stress regime is transtensional with an ENE-WSW $\sigma_{3}$ stress component. The past history of the edifice sector 
collapses, the potentially structurally weak zone oriented NNW-SSE, and the recent lava piling suggest the SW flank could fail again in the future. Limit Equilibrium Method and Finite Element Method analysis of slope stability of the SW flank show that:

- the edifice remains stable under gravity alone;

- a large-scale collapse could be triggered by reasonable ranges of magma pressure ( $\geq 7.7 \mathrm{MPa}$ if constant along a dyke);

- a peak ground acceleration of $\geq 460 \mathrm{~cm} / \mathrm{s}^{2}$ can also produce a large lateral failure;

- the pyroclastic deposits beneath the edifice could have been a feature that controlled the ancestral collapse;

- numerical models reveals that maximum shear strain patterns within the edifice may account for long lava flows erupted from lower vent elevations between 1600-1800 $\mathrm{m}$ asl.

\subsection{Acknowledgments}

This study was performed in the framework of the USA-Italy-France Atlantis INVOGE (International Geologic Masters in Volcanology and Geotechniques) project, and under the umbrella of the International Lithosphere Program - Task Force II. Additionally, this material is based upon work supported by the National Science Foundation under PIRE Grant No. 0530109 and the Michigan Space Grant Consortium. Thank you to Patrick Manzoni for support in the field and laboratory. 


\section{REFERENCES}

Álvarez-Gómez J, Meijer P, Martínez-Díaz J, Capote R (2008) Constraints from finite element modeling on the active tectonics of northern Central America and the Middle America Trench. Tectonics 27:1-12

Apuani T, Corazzato C (2009) Numerical model of the Stromboli volcano (Italy) including the effect of magma pressure in the dyke system. Rock Mechanics and Rock Engineering 42(1):53-72

Apuani T, Corazzato C, Cancelli A, Tibaldi A (2005a) Physical and mechanical properties of rock masses at Stromboli: a dataset for volcano instability evaluation. Bulletin of Engineering Geology and the Environment 64:419-431

Apuani T, Corazzato C, Cancelli A, Tibaldi A (2005b) Stability of a collapsing volcano (Stromboli-Italy): Limit equilibrium analysis and numerical modelling. Journal of Volcanology and Geothermal Research 144(1-4):191-210

Apuani T, Merri A, Masetti M (2007) Effects of volcanic seismic events on the Stromboli stability by finite difference numerical modeling. In: Proceedings of the International Workshop on Volcanic Rocks, 11th ISRM Congress. Ponta Delgada, Azores, Portugal, pp 101-109

ASTM (2000) Annual book of ASTM standards. ASTM Intl,

Bardinezteff J, Deniel C (1992) Magmatic evolution of Pacaya and Cerro Chiquito volcanological complex, Guatemala. Bulletin of Volcanology 54:267-283

Barton N, Choubey V (1977) The shear strength of rock joints in theory and in practice. Rock Mechanics 10:1-54

Benito M, Lindholm C, Camacho E, Climent Á, Marroquín G, Molina E, Rojas W, Escobar J, Talavera E, Alvarado G, Torres Y (2012) A new evaluation of seismic hazard for the Central America region. Bulletin of the Seismological Society of America 102(2):504-523

Bieniawski Z (1989) Engineering rock mass classifications. John Wiley and Sons Inc., New York

Bonali F, Corazzato C, Tibaldi A (2011) Identifying rift zones on volcanoes: an example from La Réunion island, Indian Ocean. Bulletin of Volcanology 73:347366

Burkhart B, Self S (1985) Extension and rotation of crustal blocks in northern Central America and effect on the volcanic arc. Geology 13:22-26 
Caceres D, Monterroso D, Tavakoli B (2005) Crustal deformation in northern Central America. Tectonophysics. 404:119-131

Carr M (1976) Underthrusting and Quaternary faulting in northern Central America. Geological Society of American Bulletin 87:825-829

Carrasco-Núñez G, Siebert L, Capra L (2011) Hazards from volcanic avalanches. Horizons in Earth Science Research 3:199-227

Conway F (1995) Construction patterns and timing of volcanism at the Cerro Quemado, Santa Maria, and Pacaya volcanoes, Guatemala. Ph.D. dissertation. In: Michigan Technological University, Houghton, p 304

Corazzato C, Francalanci L, Menna M, Petrone C, Renzulli A, Tibaldi A, Vezzoli $L$ (2008) What controls sheet intrusion in volcanoes? Petrological and structural characters of the Stromboli sheet complex, Italy. Journal of Volcanology and Geothermal Research 173:26-54

del Potro R, Hürlimann M (2008) Geotechnical classification and characterization of materials for stability analyses of large volcanic slopes. Enigneering Geology 98:1-17

Dinçer I, Altay A, Çobanoglu I, Uras Y (2004) Correlation between Schmidt hardness, uniaxial compressive strength and Young's modulus for andesites, basalts, and tuffs. Bulletin of Engineering Geology and the Environment 63:141148

Donnadieu F, Merle O (1998) Experiments on the Identation Process During Cryptodome Intrusion. Bulletin of Volcanology 63:61-72

Donnadieu F, Merle O, Besson J (2001) Volcanic edifice stability during sryptodome intrusion. Bulletin of Engineering Geology and the Environment 63(1):61-72

Eggers A (1972) The geology and petrology of the Amatitlán Quadrangle, Guatemala. PhD Dissertation, Dartmouth College

Eggers A (1983) Temporal gravity and elevation changes at Pacaya volcano, Guatemala. Journal of Volcanology and Geothermal Research 19:223-237

Elsworth D, Day S (1999) Flank collapse triggered by intrusion: the Canarian and Cape Verde Archipelagoes. Journal of Volcanology and Geothermal Research 94(1-4):323-340

Elsworth D, Voight B (1995) Dike Intrusion as a Trigger for Large Earthquakes and the Failure of Volcano Flanks. Journal of Geophysical Research 100(B4):6005-6024 
Elsworth D, Voight B (1996) Evaluation of volcano flank instability triggered by dyek intrusion. The Geological Society Special Publications 110:45-53

Feldman L (1993) Mountains of Fire, Lands that Shake: Earthquakes and Volcanic Eruptions In the Historic Past of Central America (1505-1899). Labyrinthos, Culver City, California, p 295

Franco A, Lasserre C, Lyon-Caen H, Kostoglodov V, Molina E, Guzman-Speziale M, Monterroso D, Robles V, Figueroa C, Amaya W, Barrier E, Chiquin L, Moran S, Flores O, Romero J, Santiago J, Manea M, Manea V (2012) Fault kinematics in northern Central America and coupling along the subduction interface of the Cocos Plate, from GPS data in Chiapas (Mexico), Guatemala and EI Salvador : Kinematics in northern Central America. Geophysical Journal International 189(3):1223-1236

Glicken H (1991) Sedimentary architecture of large volcanic-debris avalanches. In: Fisher R, Smith G (eds) Sedimentation in volcanic settings. Society for Sedimentary Geology Special Publications, pp 99-106

Guzman-Speziale M (2001) Active seismic deformation in the grabens of northern Central America and its relationship to the relative motion of the North America-Caribbean plate boundary. Tectonophysics 337:39-51

Hoek E (1994) Strength of rock and rock masses. ISRM News Journal 2(2):4-16

Hoek E (2007) Practical Rock Engineering. PDF:

www.rocscience.com/eduction/hoeks_corner

Hoek E, Carranza-Torres C, Corkum B (2002) Hoek-Brown failure criterion 2002 edition. Proc NARMS-TAC Conference 1:267-273

Hungr O, Salgado F, Byrne M (1989) Evaluation of three-dimensional method of slope stability analysis. Canada Geotechnical Journal 26(679-686)

Hurlimann M, Garcia-Piera J, Ledesma A (2000) Causes and mobility of large volcanic landslides: application to Tenerife, Canary Islands. Journal of Volcanology and Geothermal Research 103(1-4):121-134

Hürlimann M, Mart J, Ledesma A (2000) Mechanical relationship between catastrophic volcanic landslides and caldera collapse. Geophysical Research Letters $27(2393-2396)$

Hynes M, Franklin A (1984) Rationalizing the Seismic Coefficient Method. U.S. Department of the Army. Waterways Experiment Station. U.S. Army Corps of Engineers, Miscellaneous Paper GL-84-13 
IGN, Bonis S (1993) Mapa Geologico de Guatemala Escala 1:250,000. Hoja ND 15-8-G, "Guatemala". First edition (map), Guamatala

IGN, Eggers A (1969) Mapa geologico de Guatemala escala 1:50,000. Hoja 2059 II G, "Amatitlan". First edition (map), Guatemala

ISRM (1981) Rock characterisation testing and monitoring. In: Brown E (ed) Pergamon Press, Oxford

Iverson R (1995) Can magma-injection and groundwater forces cause massive landslides on Hawaiian volcanoes? Journal of Volcanology and Geothermal Research 66(295-308)

JICA, INSIVUMEH, SEGEPLAN (2003) Estudio del establecimiento de los mapas básicos de amenaza para el sistema de información geográfica de la República de Guatemala. In: Final report executive abstract (unpublished). p 206

Kitamura S, Matías Gómez R (1995) Tephra stratigraphic approach to the eruptive history of Pacaya volcano, Guatemala. Science Reports - Tohoku University, Seventh Series. Geography 45(1):1-41

Lyon-Caen Hea (2006) Kinematics of the North America-Caribbean- Cocos plates in Central America from new GPS measurements across the PolochicMotagua fault system. . Geophysical Research Letters 33: p 5

Manzoni P (2012) Slope stability analysis of the Pacaya Volcano, Guatemala, using Limit Equilibrium and Finite Element Method. MS thesis, Michigan Technological University

Marinos P, Hoek E (2000) GSI - A geologically friendly tool for rock mass strength estimation. In: Proc. GeoEng 2000 Conference. Melbourne, Australia, pp 1422-1442

Matías Gómez R (2009) Volcanological map of the 1961-2009 eruption of Volcán de Pacaya, Guatemala. MS thesis, Michigan Technological University

Matías Gómez R, Rose W, Palma J, Escobar-Wolf R (2012) Notes on a Map of the 1961-2010 Eruptions of Volcán de Pacaya, Guatemala. Geological Society of American Digital Map Chart Series 10: p 10

Michalowski R (2010) Limit Analysis and Stability Charts for 3D Slope Failures. Journal of Geotechnical and Geoenvironmental Engineering 136:583-593

Nakamura K (1977) Volcanoes as possible indicators of tectonic stress oreintation- principle and proposal. Journal of Volcanology and Geothermal Research 2(1):1-16 
Reid M, Christian S, Brien D (2000) Gravitational stability of three-dimensional stratovolcano edifices. Journal of Geophysical Research 105(B3):6043-6056

Rocscience (2011) RocLab v1.0, Phase2 v 8.0, Slide v. 6.0.

Rubin A, Pollard D (1987) Origin of blade-like dykes in volcanic rift zones. In: Decker RW, Wright TL Stauffer PH (Eds), Volcanism in Hawaii. . US Geological Survey Professional Papers 1350:1449-1470

Schaefer $L$ (2012) Geotechnical data and numerical analysis of edifice collapse and related hazards at Pacaya Volcano, Guatemala. MS thesis, Michigan Technological University

Schuster R, Crandell D (1984) Catastrophic debris avalanche from volcanoes. Proc. 4th Symposium on Landslides 1:567-572

Siebert L (1984) Large volcanic debris avalanches: Characteristics of source areas, deposits, and associated eruptions. Journal of Volcanology and Geothermal Research 22(163-197)

Siebert L, Alvarado G, Vallance J, van Wyk de Vries B (2006) Large-volume volcanic edifice failures in Central America and associated hazards. In: Rose WI, Bluth GJ, Carr MJ, Ewert JW, Patino LC, Vallance JW (eds), Volcanic hazards in Central America. 412:1-26

Siebert L, Béget J, Glicken H (1995) The 1883 and late-prehistoric eruptions of Augustine volcano, Alaska. Journal of Volcanology and Geothermal Research 66:367-395

Siebert L, Glicken H, Ui T (1987) Volcanic hazards from Bezymianny- and Bandai- type eruptions. Bulletin of Volcanology 49(1):435-459

Sousa J, Voight B (1995) Multiple-pulsed debris avalanche emplacement at Mount St. Helens in 1980: Evidence from numerical continuum flow simulations. Journal of Volcanology and Geothermal Research 66(227-250)

Thomas M, Petford N, Bromhead E (2004) Volcanic rock-mass properties from Snowdonia and Tenerife: implications for volcano edifice strength. Journal of the Geological Society 161:939-946

Tibaldi A, Lagmay A (2006) Interaction between volcanoes and their basement. Journal of Volcanology and Geothermal Research 158(1-5)

Ui T (1987) Discrimination between debris avalanche deposits and other volcaniclastic deposits. In: Latter J (ed) Volcanic Hazards. Berlin: SpringerVerlag, pp 201-209 
Ui T, Takarada S, Yoshimoto M (2000) Sigurdsson H, Houghton B, McNutt S T, Rymer H, Stix J (eds) Encyclopedia of Volcanoes. . Academic Press, San Diego

Ui T, Yamamoto H, Suzuki K (1986) Characterization of debris avalanche deposits in Japan. Journal of Volcanology and Geothermal Research 29:231243

Vallance J, Siebert L, Rose W, Raul Girón J, NG B (1995) Edifice collapse and related hazards in Guatemala. Journal of Volcanology and Geothermal Research 66:337-355

Voight B (2000) Structural stability of andesite volcanoes and lava domes.

Philosophical Transactions of the Royal Society of London 358:1663-1703

Voight B, Elsworth D (1997) Failure of volcano slopes. Géotechnique 47(1):1-31

Voight B, Elsworth D (2000) Instability and Collapse of Hazardous Gaspressurized Lava Domes. Geophysical Research Letters 27(1):1-4

Voight B, Glicken H, Janda R, Douglass P (1981) Catastrophic rockslide avalanche of May 18. In: P.W. Lipman and D.R. Mullineaux (Editors). The 1980 Eruptions of Mount St. Helens, Washington. U.S. Geological Surveys Professional Papers 1250(98):347-378

Voight B, Janda R, Glicken H, Douglass P (1983) Natura and mechanics of the Mount St Helens rockslide-avalanche of 18 May 1980. Géotechnique 33:243-273

Walker J (1989) Caribbean arc tholeiites. Journal of Geophysical Research 94:10539-10548

Watters R, Delahaut W (1995) Effect of Argilic Alteration on Rock Mass Stability. In: Haneburg W, Anderson S (eds) Reviews in Engineering Geology. Geological Society of America, Boulder, CO, pp 139-150

Watters R, Zimbelman D, Bowman S, Crowley J (2000) Rock Mass Strength Assessment and Significance to Edifice Stability, Mount Rainier and Mount hood, Cascade Range Volcanoes. Pure Applied Geophysics 157:957-976

Wunderman R, Rose W (1984) Amatitlán, an actively resurging caludron $10 \mathrm{~km}$ of Guatemala City. Journal of Geophysical Research 89:8525-8539

Wyllie D, Mah C (2004) Rock Slope Engineering, Civil and Mining. Spon Press, New York

Zimbelman D, Watters R, Bowman S, Firth I (2003) Quantifying Hazard and Risk Assessments at Active Volcanoes. Eos Transactions, American Geophysical Union 84(23):216-217 
Zimbelman D, Watters R, Firth I, Briet G, Carrasco-Núñez G (2004)

Stratovolcano stability assessment methods and results from Citlatlépetl Mexico.

Bulletin of Volcanology 66(1):66-79 
APPENDIX A: Rose diagrams (strike direction) of principal discontinuities at each survey site

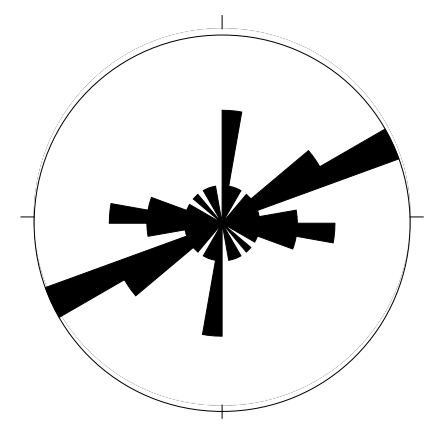

Figure A-1 Site S01 $(n=22)$

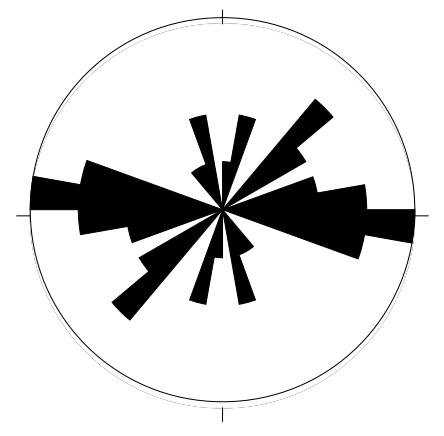

Figure A-3 Site S03 $(n=24)$

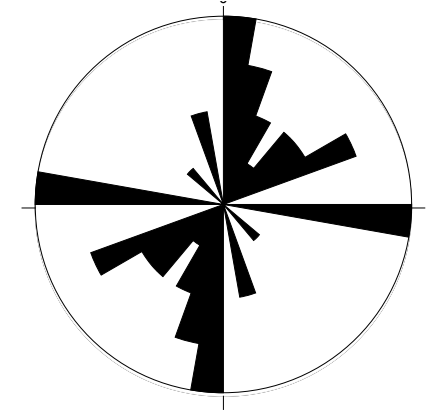

Figure A-5 Site S05 ( $n=24)$

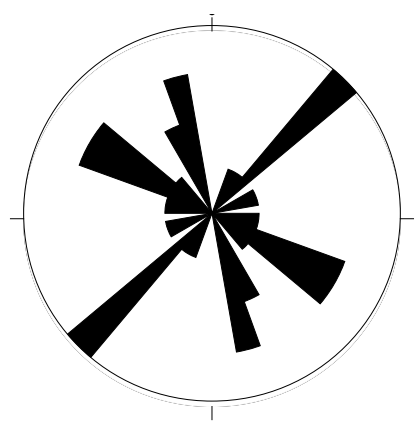

Figure A-2 Site $\mathrm{S} 02(n=26)$

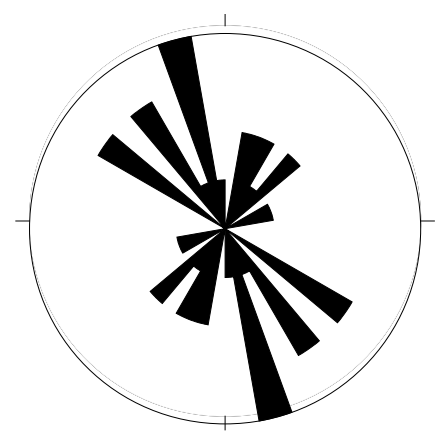

Figure A-4 Site S04 $(n=21)$

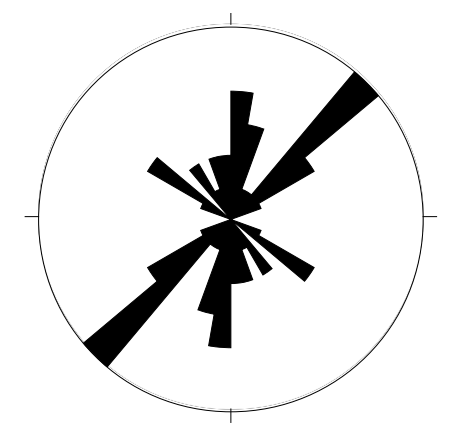

Figure A-6 Site S06 $(n=30)$ 


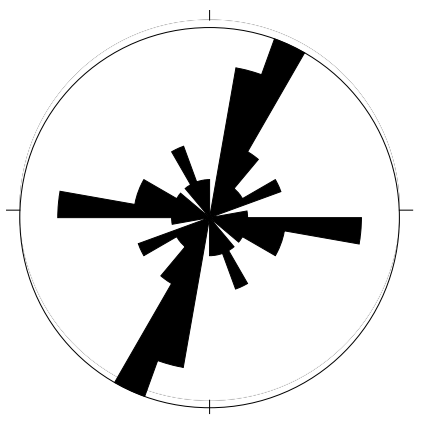

Figure A-7 Site S07 $(n=30)$

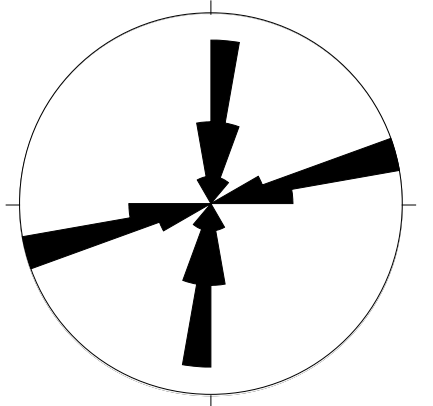

Figure A-9 Site S09 (n=28)

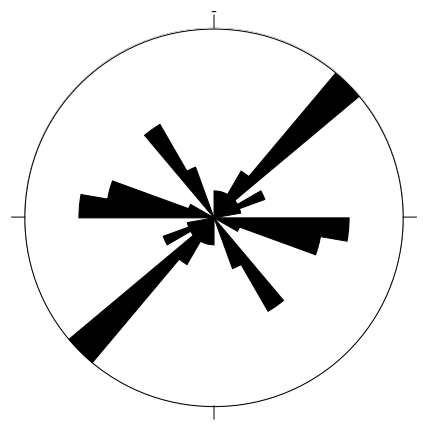

Figure A-8 Site S08 $(n=32)$

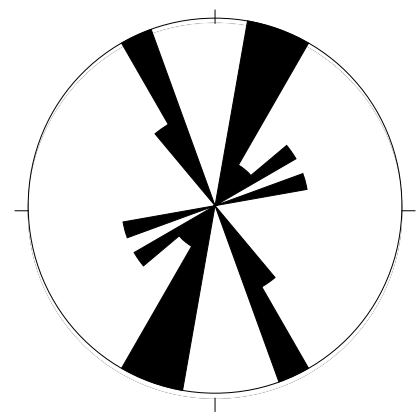

Figure A-10 Site $S 10(n=20)$ 


\section{APPENDIX B: Geotechnical survey results}

The following are descriptions of each field site based on scanline surveys following International Society for Rock Mechanics procedures and using suggestions from del Potro and Hürlimann (2008). JRC= Joint Roughness Coefficient from Barton and Choubey (1977). $\mathrm{P} \ell=$ persistence length, and $\mathrm{Pa}=$ persistence area.

\section{Table B-1}

\section{Site S01}

\begin{tabular}{|l|ccc|}
\hline Joint set & K1 & K2 & K3 \\
\hline JRC & 6 to 8 & 8 to 10 & 14 to 16 \\
Opening $(\mathbf{m m})$ & $25.4-152.4$ & $63.5-76.2$ & 25.4 \\
Infill & partially filled with soil & soil & soil \\
Alteration & discolored & discolored & discolored \\
Filtration & none & none & none \\
Pe & $50-90$ & $50-90 \%$ & $<25 \%$ \\
Pa & $25-80$ & $<25 \%$ & $<25 \%$ \\
Directional length $(\mathbf{m})$ & 4 & 1.27 & 1.5 \\
Directional immersion $(\mathbf{m})$ & 8 & 9 & 2 \\
Termination & $\mathrm{Td}$ & Td or Tx & Td \\
\hline
\end{tabular}

Table B-2

Site S02

\begin{tabular}{|l|cccc|}
\hline Joint set & K1 & K2 & K3 & K4 \\
\hline JRC & 6 to 8 & 2 to 4 & 14 to 16 & 12 to 14 \\
Opening $(\mathbf{m m})$ & $1-2$ in & 3 in & 0.5-1in & 1 in \\
Infill & completely filled soil & soil & soil & soil \\
Alteration & slightly & discolored & discolored & discolored \\
Filtration & none & none & none & none \\
Pe & $50-90 \%$ & $50-90 \%$ & $<25 \%$ & $<25 \%$ \\
Pa & $<25 \%$ & $<25 \%$ & $<25 \%$ & $<25 \%$ \\
Directional length $(\mathbf{m})$ & 1.52 & 1.73 & 1.85 & 1.65 \\
Directional immersion $(\mathbf{m})$ & 1.73 & 3.12 & 1.07 & 0.69 \\
Termination & $\mathrm{Td}$ & $\mathrm{Td}$ & $\mathrm{Td}$ & $\mathrm{Td}$ \\
\hline
\end{tabular}




\section{Table B-3}

Site S03

\begin{tabular}{|l|ccc|}
\hline Joint set & K1 & K2 & K3 \\
\hline JRC & 6 to 8 & 8 to 10 & 14 to 16 \\
Opening $(\mathbf{m m})$ & $25.4-152.4$ & $63.5-76.2$ & 25.4 \\
Infill & partially filled with soil & soil & soil \\
Alteration & discolored & discolored & discolored \\
Filtration & none & none & none \\
Pe & $50-90$ & $50-90 \%$ & $<25 \%$ \\
Pa & $25-80$ & $<25 \%$ & $<25 \%$ \\
Directional length $(\mathbf{m})$ & 4 & 1.27 & 1.5 \\
Directional immersion $(\mathbf{m})$ & 8 & 9 & 2 \\
Termination & $\mathrm{Td}$ & Td or Tx & $\mathrm{Td}$ \\
\hline
\end{tabular}

\section{Table B-4}

Site S04

\begin{tabular}{|l|cccc|}
\hline Discontinuity & K1 & K2 & K3 & K4 \\
\hline JRC & 10 to 12 & 16 to 18 & 14 to 16 & 14 to 16 \\
Opening $(\mathbf{m m})$ & $25.4-100$ & closed & closed & $12.7-25.4$ in \\
Infill & soil & soil & soil & soil \\
Alteration & discolored & discolored & discolored & discolored \\
Filtration & none & none & none & none \\
Pe & $>90$ & 50 to $90 \%$ & $<50 \%$ & $<50$ \\
Pa & $25-80$ & $<25 \%$ & $<25 \%$ & $<25$ \\
Directional length $(\mathbf{m})$ & 2 & 1.2 & 0.5 & \\
Directional immersion $(\mathbf{m})$ & 1.27 & 4.5 & 0.5 & \\
Termination & $\mathrm{Td}$ & $\mathrm{Td}$ & $\mathrm{Td}$ & $\mathrm{Td}$ \\
\hline
\end{tabular}

Table B-5

Site S05

\begin{tabular}{|l|ccc|}
\hline Discontinuity & K1 & K2 & K3 \\
\hline JRC & 8 to 10 & 12 to 14 & 14 to 16 \\
Opening (mm) & 25.4 & 12.7 & 25.4 \\
Infill & completely filled soil & soil & soil \\
Alteration & slightly & slightly weathered & slightly weathered \\
Filtration & none & none & none \\
Pe & $50-90 \%$ & $50-90 \%$ & $<50 \%$ \\
Pa & $<25 \%$ & $25-80 \%$ & $<25 \%$ \\
Directional length $(\mathbf{m})$ & 0.25 & & 0.66 \\
Directional immersion $(\mathbf{m})$ & 0.18 & $0.23-0.38$ in & 0.43 \\
Termination & Td & Td & Td \\
\hline
\end{tabular}




\section{Table B-6}

Site S06

\begin{tabular}{|l|cc|}
\hline Joint set & K1 & K3 \\
\hline Type & joint & joint \\
JRC & 8 to 10 & 12 to 14 \\
Opening (mm) & $0.5-152$ & $25.4-50$ \\
Infill & completely filled soil & soil \\
Alteration & slightly weathered & slightly weathered \\
Filtration & none & none \\
Pe & $>90 \%$ & $>90 \%$ \\
Pa & $25-80 \%$ & $25-80 \%$ \\
Directional length $(\mathbf{m})$ & 180 in & 7 \\
Directional immersion & 5 & 4 \\
(m) & Td-Tx & Tx \\
Termination & & \\
\hline
\end{tabular}

\section{Table B-7}

\section{Site S07}

\begin{tabular}{|l|cccc|}
\hline Joint set & K1 & K2 & K3 & K4 \\
\hline Type & joint & joint & joint & joint \\
JRC & 12 to 14 & 12 to 14 & 8 to 10 & 14 to 16 \\
Opening (mm) & $25.4-76.2$ & 12.7 & $12.7-25.4$ & $12.7-25.4$ \\
Infill & partially filled soil & soil & soil & soil \\
Alteration & slightly & slightly weathered & slightly weathered & slightly weathered \\
Filtration & none & none & none & none \\
Pe & $<50 \%$ & $<50 \%$ & $>90 \%$ & $<50 \%$ \\
Pa & $25-80 \%$ & $<25 \%$ & $>80 \%$ & $25-80 \%$ \\
Directional length (m) & 0.61 & 0.13 & $0.18-0.61$ & $0.05-0.41$ \\
Directional immersion & 0.89 & $0.23-0.61$ & $0.48-0.94$ & $0.66-0.79$ \\
(m) & $\mathrm{Tr}$ & $\mathrm{Td}$ & $\mathrm{Tr}$ & $\mathrm{Td}$ \\
Termination & & & & \\
\hline
\end{tabular}




\section{Table B-8}

\section{Site S08}

\begin{tabular}{|l|ccc|}
\hline Joint set & K1 & K2 & K3 \\
\hline Type & joint & joint & joint \\
JRC & 12 to 14 & 8 to 10 & 8 to 10 \\
Opening (m $)$ & $0-12.7$ & 12.7 & 12.7 \\
Infill & partially filled soil & soil & soil \\
Alteration & slightly & slightly weathered & slightly weathered \\
Filtration & none & none & none \\
Pe & $<50 \%$ & $>90 \%$ & $>90 \%$ \\
Pa & $25-80 \%$ & $25-80 \%$ & $25-80 \%$ \\
Directional length $(\mathbf{m})$ & 1 & 3.5 & 3.5 \\
Directional immersion & 5 & 5 & 5 \\
(m) & Td & Td-Tx & Tx-Td \\
Termination & & & \\
\hline
\end{tabular}

\section{Table B-9}

\section{Site S09}

\begin{tabular}{|l|ccc|}
\hline Joint set & K1 & K3 & K4 \\
\hline JRC & 16 to 18 & 12 to 14 & 12 to 14 \\
Opening (mm) & 5.08 & 5.08 & 12.7 \\
Infill & partially filled soil & soil & soil \\
Alteration & slightly & slightly weathered & slightly weathered \\
Filtration & none & none & none \\
Pe & $<50 \%$ & $50-90 \%$ & $50-90 \%$ \\
Pa & $<25 \%$ & $<25 \%$ & $25-80 \%$ \\
Directional length $(\mathbf{m})$ & 0.56 & 0.48 & $0.3-1.14$ \\
Directional immersion & $0.25-0.61$ & 0.81 & $0.23-0.76$ \\
(m) & Td & Tx-Td & Td \\
Termination & & & \\
\hline
\end{tabular}

\section{Table B-10}

Site S10

\begin{tabular}{|l|cc|}
\hline Joint set & K1 & K3 \\
\hline JRC & 4 to 6 & 8 to 10 \\
Opening (mm) & $25.4-76$ & 38 \\
Infill & partially filled soil & soil \\
Alteration & slightly & slightly weathered \\
Filtration & none & none \\
Pe & $>90 \%$ & $>90 \%$ \\
Pa & $>80 \%$ & $>80 \%$ \\
Directional length (m) & 1.93 & 2.62 \\
Directional immersion & 2.59 & 4.14 \\
$(\mathbf{m})$ & Td-Tx & Tx-Td \\
Termination & & \\
\hline
\end{tabular}

